\title{
The Role of microRNAs and alternative polyadenylation in Modulating the p53 Response
}

\author{
Jared Browning
}

A thesis submitted to the Faculty of Graduate and Postdoctoral Affairs in partial fulfillment of the requirements

For the degree of

Master of Science

In

\section{Biology}

Carleton University

Ottawa, Ontario

(C) 2018 Jared Browning 


\begin{abstract}
The p53 protein is an important tumor-suppressor that is negatively regulated by MDM2, itself a p53-induced protein. Here we used nutlin-3A, a reversible inhibitor of MDM2, to activate the p53 response in HCT116 cells and isogenic miRNA-processing defective Drosha and Dicer knockout sublines, to determine the role of miRNAs in this feedback loop. We provide evidence that miRNAs inhibit MDM2 mRNA and protein levels when cells are exposed to nutlin-3A twice, separated by a period of recovery. Surprisingly, MDM2 transcripts with the longest 3'UTRs escaped miRNA-mediated repression, while specific isoforms with shorter 3'UTRs were attenuated in parental cells and over-expressed in the miRNA processing defective knockouts. We propose that miRNA recognition sites are placed in a more accessible context within these shorter 3'UTR variants. Thus, polyadenylation site selection represents a novel regulatory mechanism in the p53 response, with the potential to impact the p53-MDM2 feedback loop and p53-mediated tumor suppression.
\end{abstract}




\section{Acknowledgements}

I would like to thank my supervisor Dr. Bruce McKay for all of his support and guidance throughout my research, in working on this thesis his endless guidance and input has provided me with so much knowledge and experience. I would also like to thank the members of my committee Dr. Marc Ekker and Dr. Kyle Biggar for their contributions.

Next I would like to thank Teeghan Rambo for her exceptional hard work, as a major part of this project Teeghan provided the presented immunoblots, contributed to Random primer/OligodT qRT-PCR data and 3'RACE sequencing results. My thanks also goes to everyone in the McKay lab for creating a positive environment that helped make my time in this lab a great experience.

I would also like to thank my family and friends for their support, listening to all of my science lectures and helping me stay positive throughout my studies and research. 


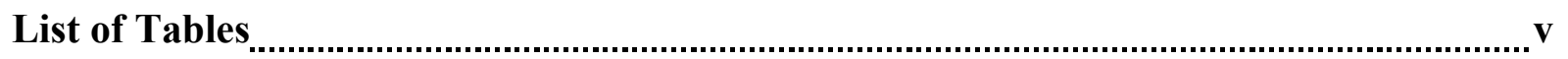

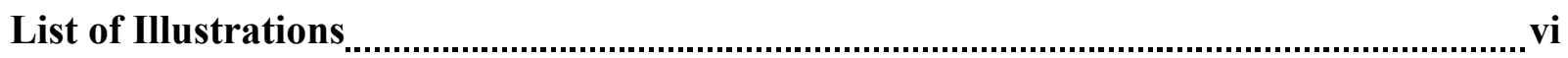

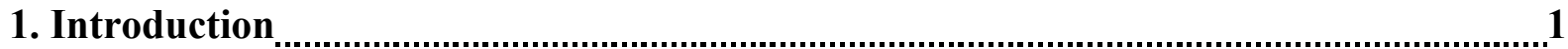

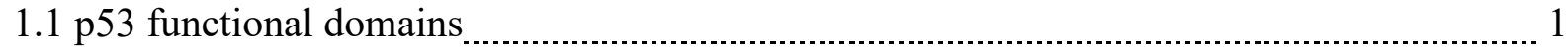

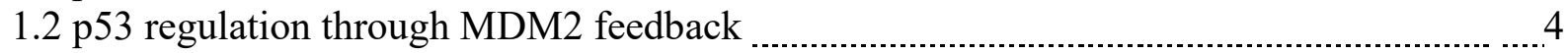

1.3 p53 Network

1.4 miRNA processing

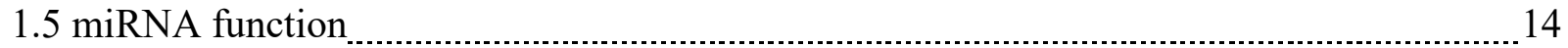

1.6 p53 protein and miRNAs $\ldots$

1.7 Polyadenylation and 3'UTR

1.8 p53 protein and 3'END processing

1.9 Rationale $\ldots$

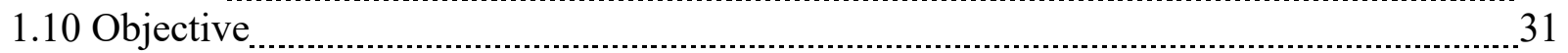

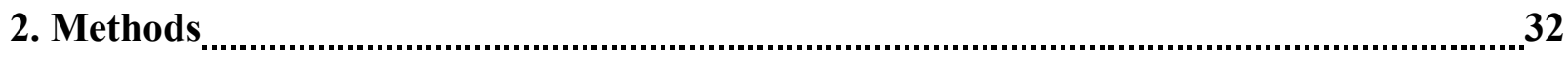

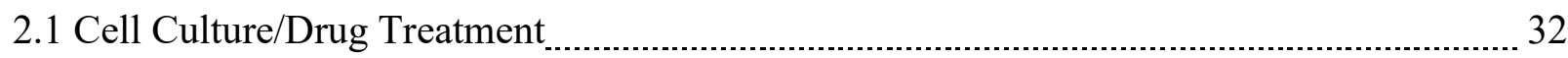

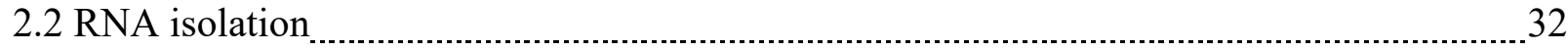

2.3 Reverse Transcription and qRT-PCR $\ldots$

2.4 3'RACE

2.5 DNA purification

2.6 Protein quantification and Immunoblot $\ldots$

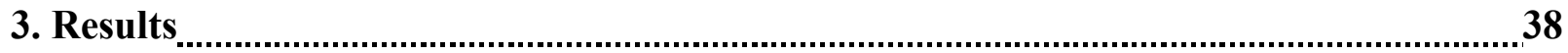

3.1 Absence of miRNA feedback in response to long term nutlin-3A exposure _................... 38

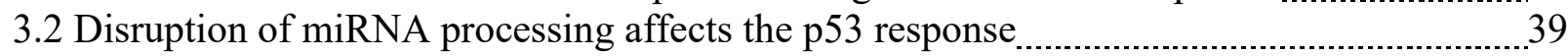

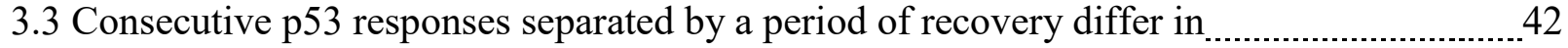
the presence of miRNAs

3.4 MDM2 3'UTR changes dynamically during p53 activation in the _................................... 47 presence/absence of miRNAs

4. Discussion 53

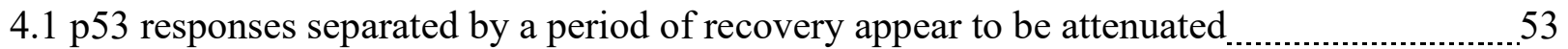
in the presence of miRNAs

4.2 p53 responses separated by a period of recovery in miRNA $\ldots$ deficient cells are not attenuated

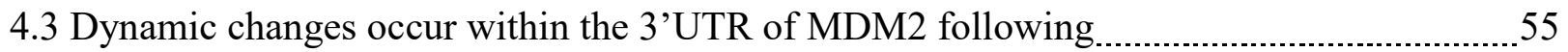
p53 activation

4.4 Drosha and Dicer knockout effects on cells

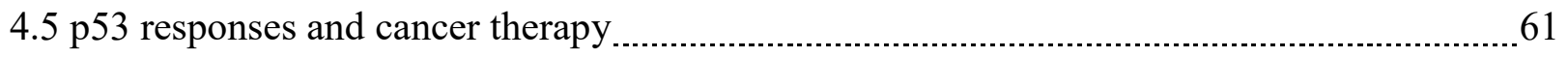

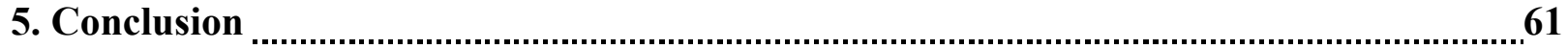

6. References $\ldots$ 
List of Tables

Page \#

Table 1 Primer sequences

Table 2 Double induction mRNA values

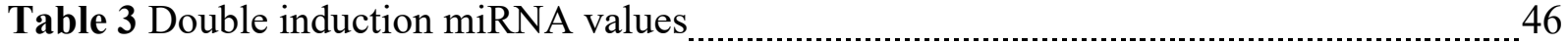


List of Illustrations

Page \#

Figure 1 p53 protein structure

Figure 2 MDM2 feedback loop

Figure 3 p53 network: mRNAs

Figure 4 microRNA processing

Figure 5 p53 network: mRNAs \& miRNAs $\ldots \ldots \ldots$

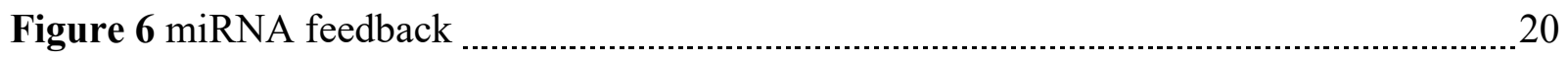

Figure 7 3'UTR elements $\ldots \ldots \ldots \ldots$

Figure 8 Polyadenylation mechanisms

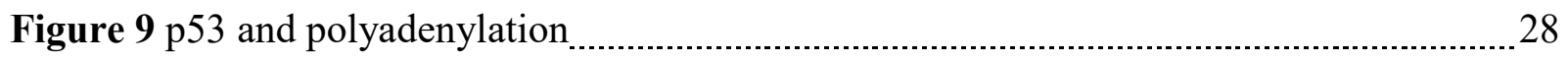

Figure 10 miRNA modulation model

Figure 11 sustained p53 activation

Figure 12 Knockout effects on miRNA and first response $\ldots \ldots \ldots$

Figure 13 Double induction mRNAs

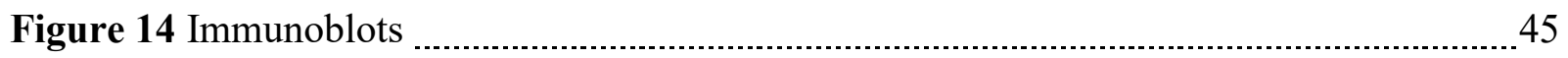

Figure 15 Double induction miRNAs

Figure 16 MDM2 3'UTR_

Figure 17 Random primer 3'UTR expression

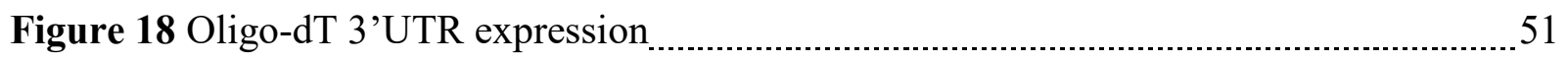

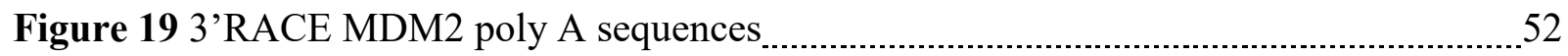




\section{Introduction}

\section{1 p53 Functional Domains}

It has been over 40 years since the discovery of the p53 protein and to date there are still aspects of its vast network that have yet to be discovered. The p53 protein is a tumor suppressor that is among the most commonly altered proteins in diverse cancer, with mutations or deletions present in nearly 50\% of human cancers (Heintz et al., 2017). Research has focused on the role p53 plays in preventing tumorigenesis, and how mutated p53 allows cancer cells to proliferate. Acting as a transcriptional regulator p53 directly controls many genes, a recent meta-analysis has identified 346 unique high confidence mRNA targets in the literature, with many others exhibiting selective patterns of expression (Fischer, 2017). Activation of the p53 network occurs through signaling pathways elicited by DNA damage, this can come in many forms including; UV damage, chemo- and radio-therapies. Although, p53 is also capable of activation by heat shock, hypoxia, metabolic stress, ribosomal stress and, nucleotide depletion (Apella \& Anderson, 2001). Once activated, a host of downstream targets are induced leading to either DNA damage repair, or depending on the damage, cell cycle arrest, senescence or apoptosis.

p53 can be found in almost every cell in the body, where it is constantly expressed and degraded to maintain low levels. As a transcriptional factor this protein is comprised of multiple domains including; two N-terminal transactivation domains (TAD1 and TAD2), a proline rich domain, central DNA-binding domain, nuclear localization domain, oligomerization domain and an unstructured C-terminal domain (Figure 1) (Sullivan et al., 2018). Transactivation domains 1 and 2 are located in the N-terminal region of p53 (residues $\sim 1-40$ and $\sim 40-61$ ), playing a major role in its tumor suppressing abilities, with inactivation of these domains completely abolishing tumor suppressing function. Interestingly, inactivation of one domain is not sufficient enough to 
abolish tumor suppressing function, p53, therefore, only requires one TAD in order to function (Brady et al., 2011; Smith et al., 2007). In humans there is evidence of interchangeable binding of each subdomain to targets, however, there is no difference in the contribution of each subdomain to the p53 response itself (Smith et al., 2007). These domains are one of the most potent activation domains, having similar strength to the herpes virus protein VP16 (Fields \& Jang, 1990). Both subdomains are highly conserved in primates, with subdomain 2 being poorly conserved in rodents, adding complexity to the use of TAD models between humans and mice.

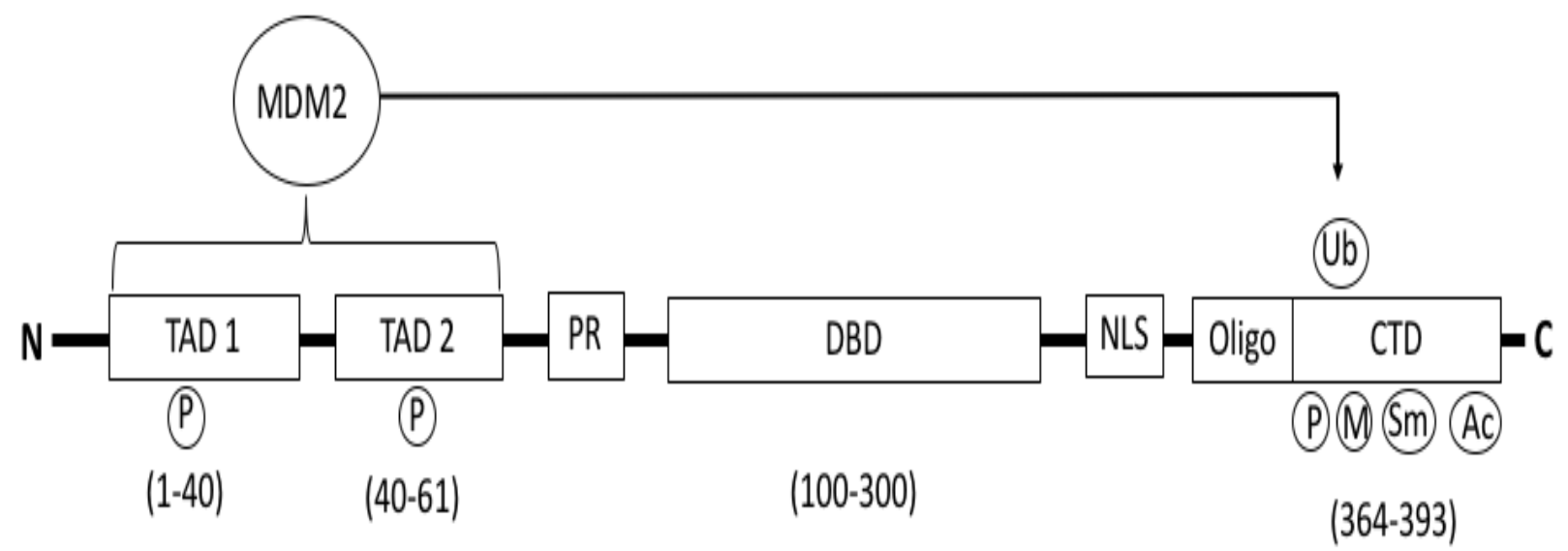

Figure 1. p53 protein structure with post-translational modification regions. Starting at the Nterminal there are two transactivation domains TAD1 and TAD 2, followed by the proline rich region (PR), core DNA binding domain (DBD), nuclear localization signal (NLS), the oligomerization domain (Oligo) and finally the C-terminal domain (CTD). MDM2 binds to the TAD domains, blocking their action and simultaneously ubiquitinates (Ub) the CTD leading to degradation of $\mathrm{p} 53$. Additional modifications include phosphorylation (P), acetylation (Ac) methylation (M) and sumoylation (SM).

Following the transactivation domains are the proline rich domain (residues $\sim 64-92$ ), and the DNA binding domain. The proline rich domain is a stretch of five copies of PXXP and is known to play a role in p53 mediated apoptosis (Baptiste et al., 2002). It is also a docking site for signaling proteins and has been reported to act as an SH3 domain, having effects on cell proliferation (Alexandropoulos et al., 1995; Lee et al., 1996). Binding of proteins to this region 
requires proper conformation of other adjacent regions, primarily being the DNA binding domain. Conformation of these regions may allow specific proteins to bind and act as a final regulatory event in signaling pathways affecting proliferation. One specific example is a reported interaction with growth arrest specific 1 (GAS1) signaling protein, involved in regulating cell growth arrest (Ruard et al., 1997).

In similarity to the TAD domains, there are two DNA binding domains within p53, although, they are not located in the same region. The first is the core domain that binds sequence specific DNA (residues $\sim 100-300$ ), and the other is a non-sequence specific domain in the Cterminal that aids in anchoring and stabilization (Figure 1) (McKinney \& Prives, 2002; McKinney et al., 2004; Hamard et al., 2012; Kim et al., 2012; Laptenko et al., 2015). The DNA binding domain binds to a response element (RE) that contains two decameric palindromic sequences (half sites) separated by spacer DNA. The characterization of these REs allows p53 to form dimers, with each core domain of the protein binding to one half site of a response element (Kearns et al., 2016). Once a dimer is formed a second one may also bind on the opposite side forming the characteristic tetramer structure, this is primarily due to the oligomerization domain.

The C-terminal domain (CTD) of p53 (residues 364-393) drives non-sequence specific DNA binding activity, facilitating sliding of the protein along target genes and allowing for the DNA binding domain to recognize its REs (Figure 1) (McKinney \& Prives, 2002, Lapenko et al., 2015). CTD facilitated sliding is accomplished through electrostatic interactions that stabilize the protein during scanning and DNA binding (Friedler et al., 2005). Another important aspect of p53 is its oligomerization domain (residues $~ 323-355$ ), which is found within the CTD. A stretch of basic residues has been attributed to the ability of p53 to form tetramers from dimers (Pavletich et al., 1993). Oligomerization of p53 is key in functionality of the protein with the DNA binding 
domain working in dimers, and the CTD aiding in forming tetramers shortly after. Structure of this region transitions between an ordered and disordered state, allowing for interactions with many other factors.

Post-translational regulation of p53 takes on many forms including; ubiquitination, phosphorylation, acetylation, methylation and sumoylation (Figure 1) (Vousden \& Prives, 2009; Muller \& Vousden, 2013; Liu et al., 2015). Modifications target different sites within the p53 protein aiding in activation or repression. The N-terminal region is heavily phosphorylated when cells are exposed to genotoxic and non-genotoxic stressors. There are specific residues that are phosphorylated in non-stress conditions and dephosphorylated after DNA damage (Apella \& Anderson, 2001). Therefore, phosphorylation and dephosphorylation of residues throughout the $\mathrm{N}$-terminus shift p53 from the active to inactive state. The $\mathrm{C}$-terminal domain is also targeted as it is phosphorylated, acetylated, methylated and sumoylated at specific residues (Apella \& Anderson, 2001). Once again, these modifications can be added or removed for both non-stress and stress conditions, controlling its protein-protein and protein-DNA interactions.

\section{2 p53 Regulation through MDM2 feedback}

The most direct effect of post-translational regulation is mediated by ubiquitination of p53, which is the main function of the mouse double minute 2 (MDM2) protein. Regulation of p53 and its pathway is key in protecting cells individually or globally from transformation, and is controlled by the E3 ubiquitin ligase MDM2. The p53-MDM2 feedback loop is a tightly regulated system, MDM2 largely works through a dual action function on p53. First it binds to the N-terminal transactivation domain blocking tumor suppressive function, then MDM2 tags the C-terminal region with ubiquitin (Figure 1). This ultimately leads to p53 export from the nucleus and degradation by the proteasome complex (Hock \& Vousden, 1997; Haupt et al., 1997; Kubbutat et 
al., 1997; Marine \& Lozano, 2010). MDM2 is activated through binding of p53 to a consensus sequence in the promoter of the MDM2 gene, expressed MDM2 then feeds back to degrade expressed p53 (Figure 2). Therefore, in a normal cell nuclear MDM2 and p53 are kept at low levels.

Non-stress

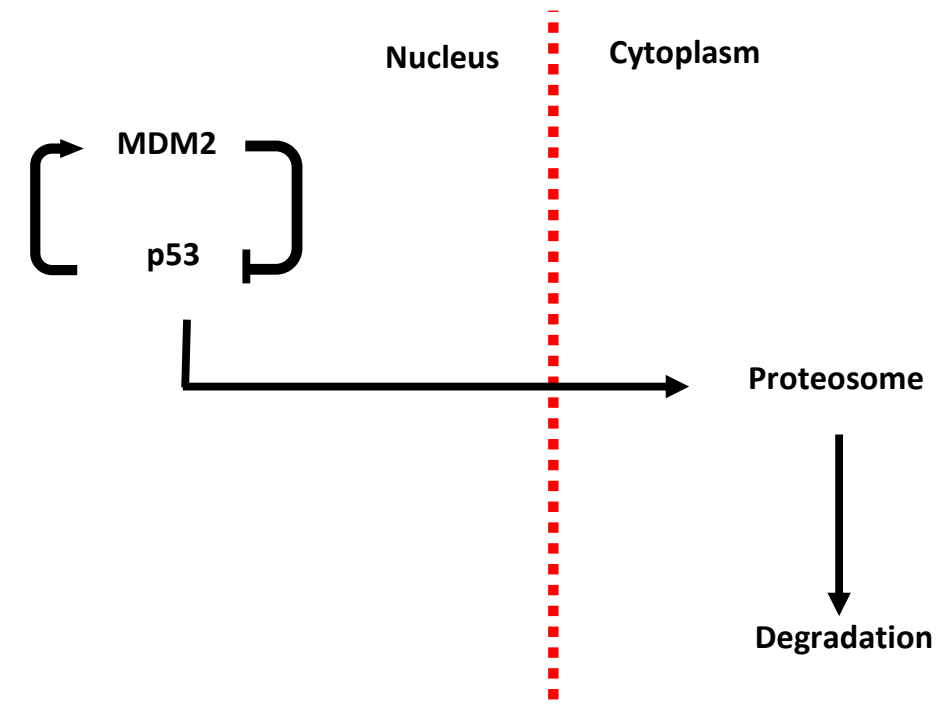

Figure 2. Non-stress regulation of p53 via the MDM2 feedback loop in normal functioning healthy cells.

Dysregulation of the MDM2 and p53 regulatory loop through overexpression of MDM2 dramatically diminishes the tumor suppressive abilities of p53. Binding of MDM2 and p53 is a highly characterized interaction, mediated by a well-defined hydrophobic surface pocket on MDM2. p53 binds within the pocket using three key residues; Phe19, Trp23 and Leu26 forming the interacting bond (Heintz et al., 2017; Kussie et al., 1996). This compact pocket has allowed for the development of small molecules that block MDM2-p53 interactions without altering expression levels. One such group of molecules are cis-imidazolines (nutlins). These were the first selective molecules to inhibit the wild type p53-MDM2 feedback loop. Binding of nutlin to MDM2 sterically inhibits binding to p53, allowing for accumulation of p53 levels within the nucleus and 
activation of its DDR response network. These molecules are suitable compounds for p53 study as they possess similar functional groups, show sufficient cell permeability and induce dose dependent accumulation of p53 (Heintz et al., 2017). In p53 null and mutant cells, they do not induce cell cycle arrest or elicit upregulation of downstream pathway components independently, indicating only wild type p53 cells are sensitive. These properties make nutlins an excellent compound in the study of the p53 response.

\section{3 p53 Network}

The p53 network can be divided up into multiple parts, the first being the input signal that induces p53 activation. The main signal that triggers a p53 response is DNA damage, this can come in the form of gamma or UV radiation, alkylation, crosslinking, depurination, alteration to deoxyribose sugars, oxidative radicals, and many other sources that compromise DNA integrity (Levine et al., 2006). Multiple proteins and enzymes work to repair DNA damage once recognized, and many are activated by different pathways induced by p53 (Giaccia \& Kastan, 1998; Gudkov \& Komarova, 2003; Oren, 2003). In order to initiate the DNA damage signal and activate p53 there needs to be an upstream factor. One major activator of p53 is the protein Ataxia-telangiectasia mutated kinase (ATM). DNA damage signals such as radiation activate ATM, which in turn phosphorylates p53 and MDM2 (Apella \& Anderson, 2001). Another protein involved in this pathway is ataxia telangiectasia and $\operatorname{Rad} 3$ (ATR3) that also phosphorylates p53 following DNA damage (Figure 3). Ultimately the phosphorylation of p53 itself and MDM2 leads to immediate p53 expression and activation of its pathway as this disrupts binding between the two proteins. A third upstream activator of p53 is ADP-ribosylation factor (ARF), this protein is activated itself by mutational inactivation of other tumor suppressors such as the transcriptional factor E2F-1, adenomatous polyposis coli (APC) or mutational activation of proto-oncogenes MYC or Ras 
(Levine et al., 2006). Alterations in these genes trigger activation of ARF leading to phosphorylation of MDM2, in turn initiating a p53 response.

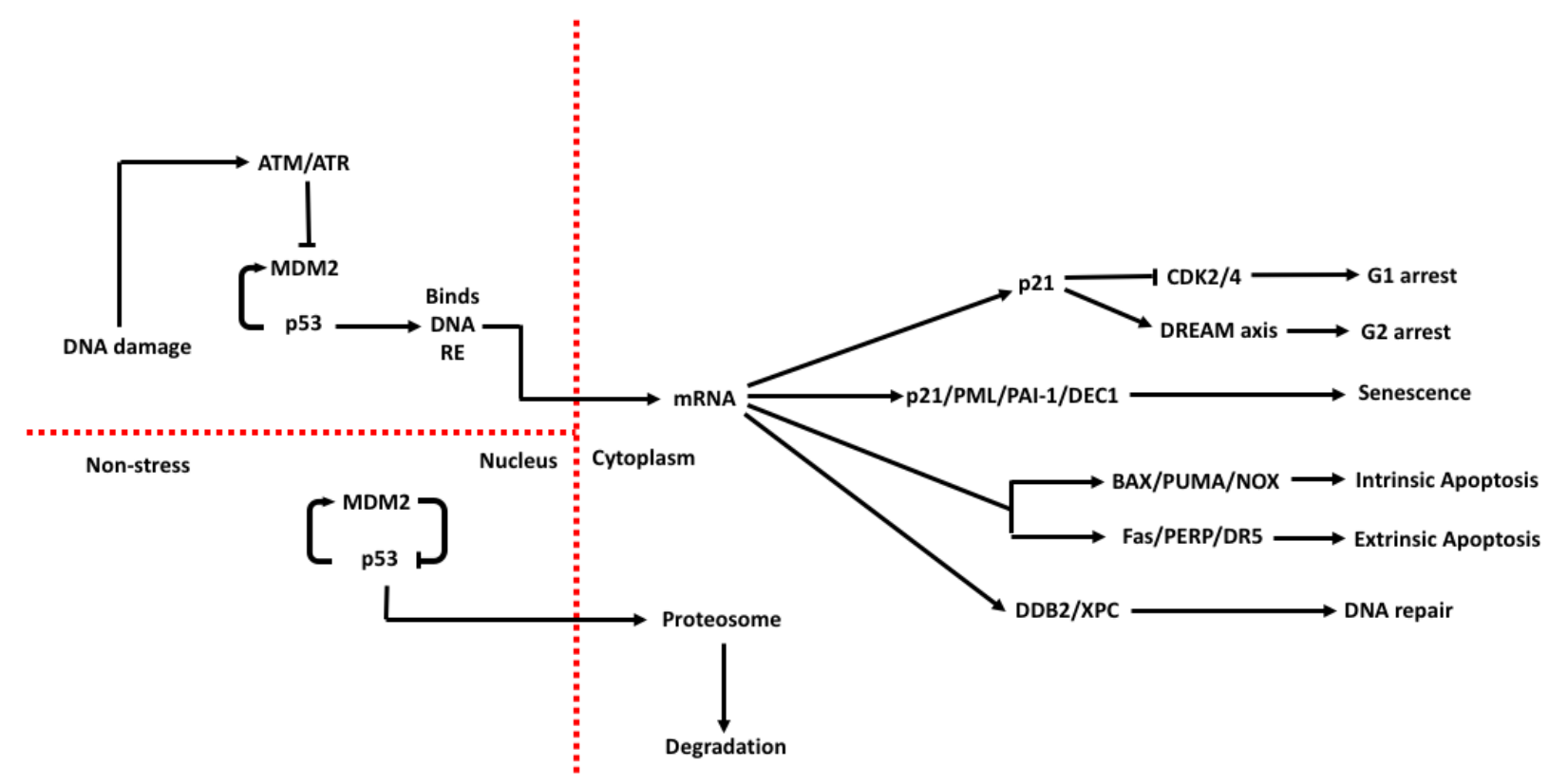

Figure 3. p53 network in both non-stress and genotoxic stress conditions. Non-stress favors the inhibitory feedback loop of MDM2 leading to p53 degradation. Genotoxic stress blocks MDM2 feedback inhibition, allowing for activation of the p53 response and its multiple downstream pathways.

The first downstream target of p53 discovered was the CDKN1A (p21) protein, a major contributor to cell cycle arrest. p53 induces cell cycle arrest primarily at the G1/S checkpoint and occasionally at the G2/M checkpoint using p21 (Figure 3). Activation of this protein can also impede the cell cycle by inhibiting CDK activity and stabilization of the DREAM complex. DREAM complex formation blocks proliferating nuclear antigen (PCNA), a critical component in DNA replication (Deng et al., 1995; Bunz et al., 1998; Luo et al., 1995; Chen et al., 1995; Harrington et al., 1998). PCNA acts as a processivity factor tethering DNA polymerase to the DNA. Multiple other p53-responsive proteins can also aid in cell cycle arrest such as; BTG2 and GADD45 (Kastan et al., 1992; Duriez et al., 2002; Guardavaccaro et al., 2000; Rouault et al., 1996; 
Wang et al., 1999), however, p21 is sufficient enough on its own to produce this cellular response, typically resulting in G1 cell cycle arrest (Levine et al., 2006). The DNA damage response (DDR) is also activated by p53, although this does not play a role in its tumor suppression it does aid in rescuing cells with minimal DNA damage (Sengupta \& Harris, 2005; Gatz \& Wiesmuller, 2005). Activation of p53 can allow for nucleotide excision repair by activating proteins such as DNA damage binding protein (DDB2), and the DNA adduct recognition protein XPC (Figure 3). It can also increase expression of a DNA polymerase capable of replicating damaged DNA (POLH) (Liu \& Chen, 2006; Lerner et al., 2016). In some cases, DNA repair may require more time delaying cell cycle progression in turn facilitating senescence.

Cell cycle arrest and senescence differ in their reversibility, cell senescence is typically noted as irreversible cell cycle arrest. This is not entirely true, as removal of p53 can produce reentrance into the cell cycle, however cells have a low survival rate following re-entrance (Beausejour et al., 2003). The difference in cell cycle arrest and senescence comes from large scale blocking of the cell cycle using; p21, PML, PAI-1, DEC1 and, BTG2 (Qian \& Chen, 2010). Large scale inhibition of the cell cycle stems from these proteins regulating signal pathways that drive cell cycle progression. PML forms a positive feedback loop enhancing p53 expression and inhibiting MDM2 control, escalating the response. PAI-1 inhibits uPA a protein that activates the MAPK pathway that drives G1/S transition. DEC1 inhibits an oncogene ID1 and BTG2 acts as an anti-proliferative, both adding to p53 control over the cell cycle (Qian \& Chen, 2010). Combined effects of these proteins lead to cell senescence over cell cycle arrest.

If cell cycle arrest and DNA repair are not viable options, p53 is capable of activating apoptotic pathways through a number of targets (Figure 3). Both the extrinsic and intrinsic pathways of apoptosis are activated by p53. The extrinsic pathway is regulated by Fas ligand 
binding to TNF receptors on the surface of the cell (Nagata \& Golstein, 1995). Both production and trafficking of Fas to the cell surface is facilitated by p53 activation, leading to TNF activation and downstream apoptotic induction (Bouvard et al., 2000; Bennett et al., 1998). The DR5/Killer death domain is another target of p53 with expression of DR5 promoting caspase- 8 induction and apoptosis (Wu et al., 1997). p53 elements are found within the PERP promoter, making it a direct p53 target (Bouillet \& Strasser, 2002). PERP is a tetra-span transmembrane protein that is activated by the hyper-proliferative factor E2F-1 and is believed to act as a cell membrane death receptor (Attardi et al., 2000). All of these methods lead to caspase-8 production and formation of the apoptosome.

Intrinsic apoptosis is largely controlled by BCL-2 proteins, regulating the release of cytochrome-c from mitochondria. Several BCL-2 pro-apoptotic proteins are controlled by p53 activation including; BAX, PUMA and NOXA (Figure 3) (Hudson et al., 2004). Once again activation of these proteins induces BCL-2 apoptotic signals, releasing cytochrome-c from the mitochondria and triggering formation of the apoptosome. Where caspase 8 and 10 are activated by death receptors in extrinsic apoptosis, in intrinsic apoptosis caspase 9 and 2 are activated by changes in mitochondrial potential leading to caspase 3 formation of the apoptosome (Maclachlan \& El-diery, 2002). On the other hand, the survival pathway is mainly regulated by protein kinase $\mathrm{B}(\mathrm{AKT})$, a protein that phosphorylates MDM2 resulting in nuclear accumulation of this protein. With MDM2 accumulating in the nucleus near p53, the inhibitory feedback loop is re-instated shutting down p53 (Mayo \& Donner, 2002). Turning off the survival pathway, p53 promotes caspase mediated cleavage of AKT, allowing for enhanced p53 activation and ultimately apoptosis (Gottlieb et al., 2002). A second method involves p53 inducing expression of the PTEN gene encoding a phosphatase PI3K that impairs AKT function. Alternatively, cyclin G can be activated, 
recruiting $\mathrm{PP} 2 \mathrm{AB}$ that dephosphorylates MDM2 at the AKT site interfering with its localization and p53 inhibition (Oren et al., 2002; Mayo \& Donner, 2002).

Interestingly given the vast effects of p53 this protein has been proven to act solely as a transcriptional activator and not a repressor. Although it has repressive downstream effects, these are mediated indirectly through activation of repressive protein genes. In the context of the cell, p53 only activates its target genes, all other effects are indirectly facilitated by its targets (Fischer et al., 2015). The p53 network is vast and controls many cellular outcomes following DNA damage. The importance of p53 makes it a prime target for mutations leading to tumor proliferation.

Mutant p53 plays many roles in cancer cell proliferation, allowing for rapid tumorigenesis due to an inhibited DDR. Studies examining the entire p53 coding sequence revealed that $86 \%$ of mutations occur in the DNA binding domain (Olivier et al., 2010). There are multiple mechanisms by which mutant p53 aids in tumorigenesis (Heintz et al., 2017). Mutations in p53 can often lead to gain of function, impacting both its transcriptional regulation and protein-protein interactions. Gain of function binding to DNA involves GC rich regions in gene promoters, both the cell cycle regulator GAS1 and HTR2A genes are bound by mutant p53 (Gohler et al., 2005; Walter et al., 2005).

Mutant p53 is capable of altered protein-protein interactions, binding to many transcriptional factors such as; Sp1, E2F-1, ETS1, CREB and p300 (Borellini \& Glazer, 1993; Di Agostino et al., 2006; Fogal et al., 2005; Giebler et al., 2000; Lee et al., 2010; Lill et al., 1997; Liu et al., 2011; Sampath et al., 2001). Binding of p53 to other tumor suppressors like p63 and p73 leads to inhibition of these proteins and aids in cancer progression. Many proteins are bound by p53 as a gain of function, allowing for forced progression through the cell cycle and inhibition of 
internal regulatory controls. Mutant p53 targets NF-Y and PLK2, both binding to CCAAT motifs in the promoters of many cell cycle regulator genes, causing increased expression and progression through the cell cycle. Mre11 is targeted by mutant p53, inhibiting its recruitment of the MRN complex that is vital in recognizing DNA damage and inducing the ATM signal pathway (Song \& $\mathrm{Hu}, 2007)$. There are a host of target genes mutant p53 uses to promote pro-invasive and proangiogenic activity, including many growth factors and chemokines. Cancer cells thrive off the expression of mutant p53 as its many gain of function mutations drive tumorigenesis.

\section{4 microRNA Processing}

Activation of the DDR and p53 response drives expression of many mRNAs and noncoding RNA molecules. Non-coding RNA are functional RNA molecules within the cell that are not translated into protein. This large category of RNA includes; rRNA, long noncoding RNA (lncRNA), circular RNA (circRNA) and micro RNA (miRNA). Non-coding RNA comprises

nearly $97 \%$ of all transcribed RNA molecules within the cell (Fesler et al., 2016). miRNAs are small non-coding single stranded RNA molecules consisting of around 20-25 nucleotides. These molecules are processed following four main steps to produce the mature 25 nucleotide miRNA duplex molecule (Figure 4). 


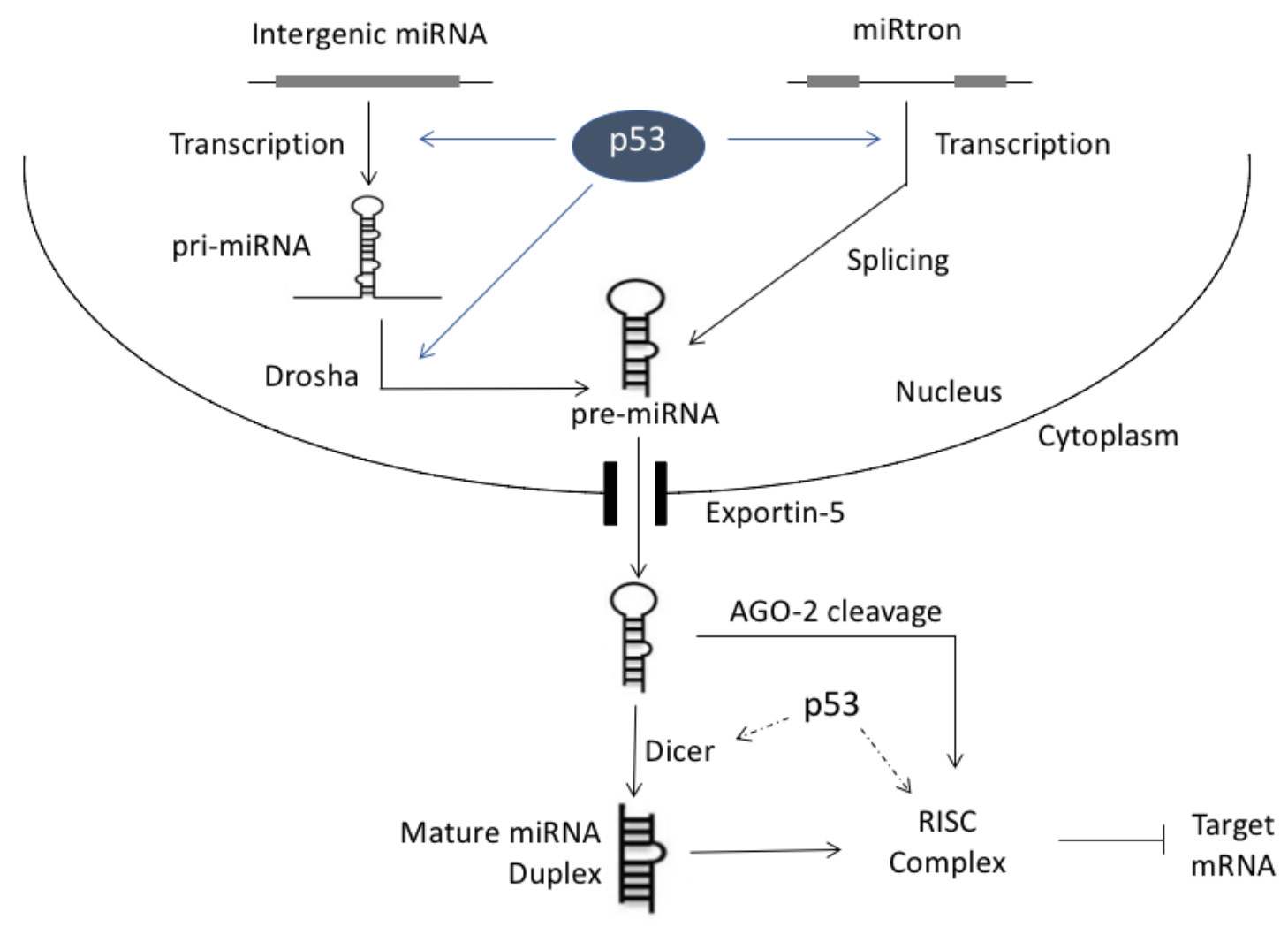

Figure 4. Canonical and non-canonical miRNA biogenesis pathways. Alternative processing pathways include bypass of Drosha cleavage enzyme by way of splicing miRNAs located in introns. Alternatively, Dicer processing may also be bypassed using the slicing capabilities of the AGO-2 protein, a major component of the active RISC complex. p53 control of miRNA biogenesis occurs directly through transcriptional interactions with miRNA genes and indirectly with other proteins affecting the Drosha/DiGeorge cleavage complex, Dicer processing and AGO-2 incorporation into the RISC complex.

RNA polymerase II first transcribes the miRNA gene from genomic DNA (intergenic, polycistronic or intronic). In this first step of transcribing the miRNA gene, the location of the gene on the chromosome alters the method in which it is processed to the pre-miRNA precursor (Figure 3). Intergenic or polycistronic miRNA genes are directly transcribed by RNA polymerase II or III (Ghildiyal \& Zamore, 2009). This generates the first precursor termed pri-miRNA, which is then cleaved into the second 70 nucleotide long precursor called pre-miRNA by the microprocessing complex consisting of the Drosha and DiGeorge Critical Region 8 (DGCR8) units. 
Drosha recognizes the proximal 10 base pairs of the pri-miRNA hairpin loop positioning its catalytic site at the base for cleavage (Han et al., 2006). miRNA genes located within introns (mirtrons) can be processed through a Drosha independent pathway (Figure 4). In this process splicing generates the non-linear intermediate that is processed by the lariat debranching enzyme, yielding the canonical hairpin loop (Okamura et al., 2007; Ruby et al., 2007).

The pre-mRNA molecule is then transported from the nucleus into the cytoplasm by the Ran-GTPase Exportin-5 (Exp5/XPO5) complex. Export from the nucleus relies on EXP-5 recognizing the 2-nucleotide overhang generated by the Drosha enzyme, and together with RanGTP carries this precursor into the cytoplasm (Bohnsack et al., 2004; Lund et al., 2006; Okada et al., 2009; Yi et al., 2003; Zeng \& Cullen, 2004). Mirtron generated pre-miRNA are also recognized by EXP-5 and follow the canonical pathway in the cytoplasm (Figure 4). Once in the cytoplasm the pre-miRNA is cleaved to the functional mature 22 nucleotide double stranded miRNA by the Dicer-transactivating response RNA-binding protein complex. At this step the Dicer enzyme accompanied by the RISC loading Complex (RLC) consisting of Tar RNA binding protein (TRBP) and protein activator of PKR (PACT) cleaves the pre-miRNA two helical turns into the hairpin (Perron \& Provost, 2008; Haase et al., 2005; Chendrimada et al., 2005; Lee et al., 2006). Although these proteins are not required for cleavage, they stabilize Dicer and aid in formation of the RISC loading complex (RLC) consisting of Dicer, TRBP and Argonaute-2 protein (AGO-2). Once this ternary structure is formed, Dicer cleaves the pre-miRNA to form the $\sim 22$ nucleotide mature miRNA duplex.

After the final processing step with Dicer the proteins TRBP and PACT dissociate from the complex following which a helicase; p68, p72 or RNA helicase A unwinds the mature miRNA duplex (Winter et al., 2011). The strand with the least stable 5'end remains in the RISC complex 
with AGO-2, while Dicer dissociates from the now active RISC complex. Once again in this second major processing step there is an alternative Dicer-independent pathway for mature miRNA formation (Figure 4). In this process the bound pre-miRNA is cleaved by AGO-2, known to have slicing capabilities as it can nick the pre-miRNA to aid in Dicer cleavage. In this case AGO-2 cleaves the pre-miRNA 10 nucleotides away from the 5' end (Daniel et al., 2010). The remaining hairpin is polyuridylated causing nuclease-mediated removal of the uredines and the unprotected template not bound by AGO-2. This leaves a mature miRNA strand bound to the AGO-2 protein that is used in the activated RISC complex. Loading of the miRNA strand activates the RISC complex where it guides this unit to target mRNA sequences, leading to degradation and silencing of these transcripts.

\section{5 microRNA function}

Once incorporated into the RISC complex miRNAs play a variety of functions throughout the cell. Activated RISC complexes bind to their targets with classical Watson Crick base pairing between the miRNA guide strand and the target mRNA 3'UTR (Wightman \& Ruvkun, 1993; Lee \& Ambros 1993). Binding is heavily reliant on the seed region of the miRNA, this region being 2-8 residues located in the 5' region of the miRNA (Brennecke et al., 2005; Doench \& Sharp, 2004; Krek et al., 2005; Lewis et al., 2003). The extent of binding between the guide strand and the mRNA changes the interaction and therefore the functional activity of the RISC complex, for example near perfect pairing favors endonuclease AGO-2 cleavage of the transcript (Bartel, 2004; Yekta et al., 2004). With activation of the RISC complex miRNAs widely function as negative regulators, with each miRNA having many potential targets throughout the cell. The two main processes through which miRNAs negatively regulate is; slicer-dependent and slicer-independent silencing. 
Slicer-dependent silencing requires extensive seed region complementarity allowing for endonuclease activity of AGO-2 as mentioned earlier. Cleavage products are then degraded first through de-adenylation, followed by either exosomal degradation $3^{\prime}-5$ ' or decapping and subsequent 5'-3' exonuclease degradation (Valencia-Sanchez et al., 2006; Parker \& Song, 2004; Coller \& Parker, 2004). Slicer-independent silencing is induced through poor seed region complementarity, leading to a bulge in the RNA duplex inhibiting AGO-2 activity (Wightman \& Ruvkun, 1993; Lee \& Ambros, 1993; Bartel, 2004). In this situation translational repression occurs through localization of mRNAs away from translational machinery, to regions such as P-bodies, or degraded through accelerated de-adenylation/de-capping (Doench et al., 2003; Bagga et al., 2005; Fischer \& Weis, 2002; Coller et al., 2001). Relocation of mRNAs to translationally inactive P-bodies is thus followed by slicer-dependent or independent degradation of the mRNA transcript, depending on the extent of base pair complementarity. Following mRNA degradation, the active RISC complex is then relocated to the P-body recruitment unit where ATP-dependent remodeling prepares the RISC complex for additional silencing function (MacFarlane et al., 2010). In the case of slicer-dependent degradation, once the mRNA is cleaved the released RISC complex is remodeled. Slicer-independent degradation recruits translational repressive machinery, taking the mRNAs for degradation or long-term storage and releasing the RISC complex for remodeling.

With processing of miRNAs beginning in the nucleus and ending in the cytoplasm the predominant function of miRNAs was believed to occur in the cytoplasm alone. However, miRNAs and argonaute proteins have been discovered within the nucleus (Jakymiw et al., 2006; Liao et al., 2010; Marcon et al., 2008; Robb et al., 2005). Import of miRNAs and RISC proteins may occur separately and then assemble in the nucleus or be imported as an active RISC complex. Shuttling has been linked to binding of import proteins such as IPO8, a known nuclear localization 
protein (Weinmann et al., 2009; Wei et al., 2014). Nuclear miRNAs have been shown to colocalize with TNRC6A, a component of the cytoplasmic RISC complex (Nishi et al, 2013). Mass spectrometry revealed the nuclear RISC complex is smaller in size than the cytoplasmic complex, meaning some factors may not be present and a minimal complex may be shuttled into the nucleus. Nuclear RISC shows an association of AGO-2 with TNRC6 (A,B,C) and AGO-3 all being more stably preserved in the nucleus, whereas in the cytoplasm AGO-2 associates with Dicer and TRBP (Kalantari et al., 2016). There appears to be a difference in the nuclear and cytoplasmic RISC complexes with core machinery perhaps shuttled into the nucleus. However, miRNAs are still shown to be functional in both the nucleus and the cytoplasm.

Functions within the nucleus remain relatively similar to the cytoplasm, with a few added functions and interactions. The miRISC complex can localize in the nucleolus and interact with rRNA, affecting their abundance as well as regulating other pre/pri-miRNA and can even remain stored as a possible defense mechanism (Bai et al., 2014; Li et al., 2013; Politz et al., 2006; Atwood et al., 2016). AGO-2 and AGO-3 are known to interact with splicing machinery, with miRNA binding sites recognized in introns as well. This can lead to the redirecting of splicing machinery and affect alternative splicing within the cell (Guil \& Caceres, 2007; Wu et al., 2010; AmeyarZazoua et al., 2012; Boudreau et al., 2014; Splenger et al., 2016; Allo et al., 2009; Liu et al., 2012). Transcriptional regulation has also been associated with nuclear miRNAs both in activating and repressing genes. Both processes involve binding within promoters and generating chromosomal changes through protein recruitment.

Functions of miRNAs are clearly vast and span not only the cytoplasm but the nucleus as well. This adds to the importance of miRNAs as regulatory factors within the cell, providing diversity to mechanisms of gene regulation. 


\section{6 p53 protein and microRNAs}

The p53 network is an enormous web that includes a host of mRNA targets and miRNAs. Regulation of miRNAs plays into the same known functions of $\mathrm{p} 53$, from apoptosis to cellular senescence. miRNAs activated by p53 act on inducing cell cycle arrest, senescence, apoptosis, inhibition of metastasis, angiogenesis and glycolysis (Figure 5) (Feng et al., 2011; Hermeking, 2012; He et al., 2007; Raver-Shapira et al., 2007).

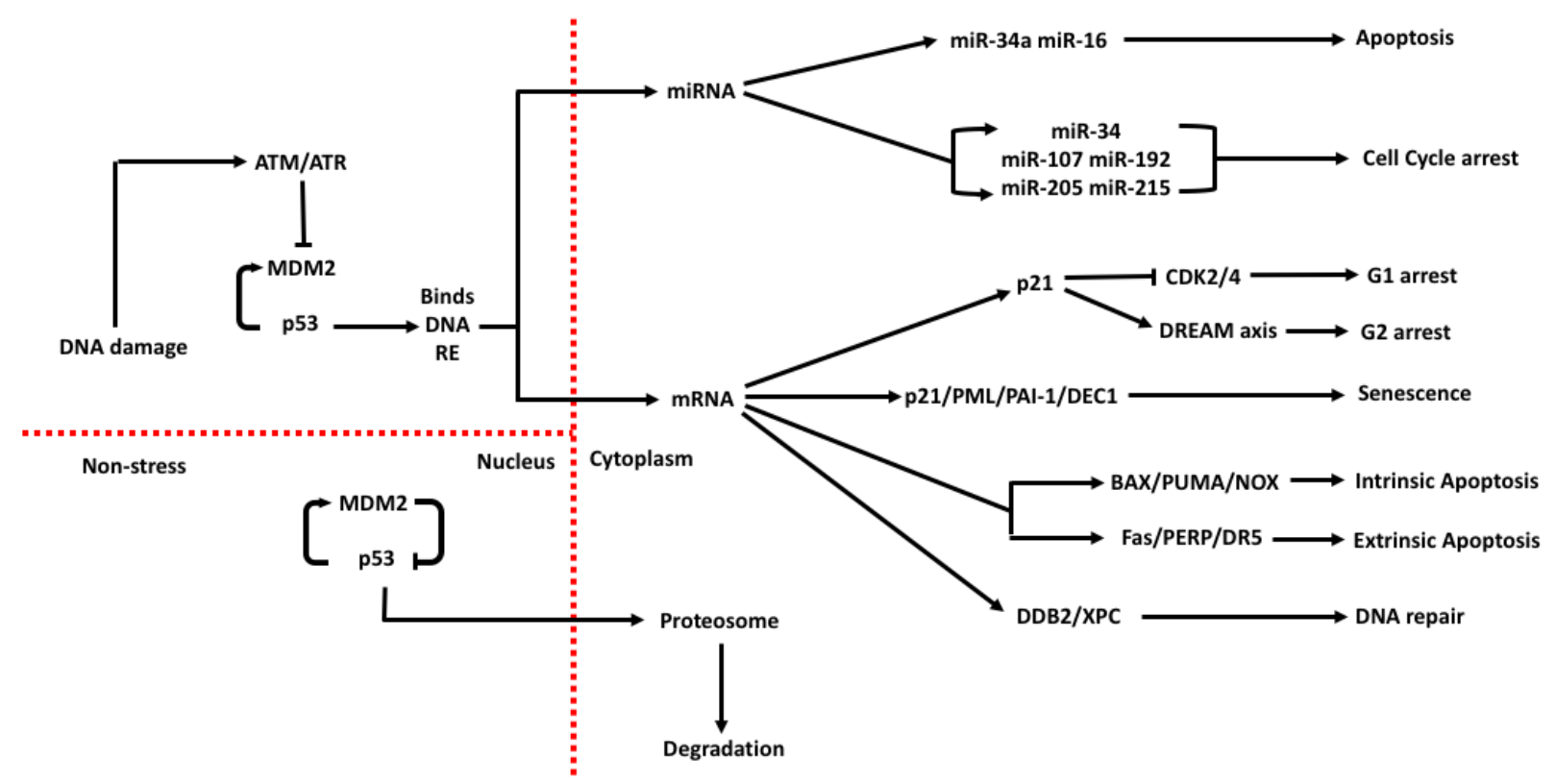

Figure 5. p53 network including non-stress and genotoxic stress conditions. Activation of p53 through DNA damaging agents leads to a number of downstream pathways that involve both mRNAs and miRNAs.

The first miRNAs found to be directly regulated by p53 was the miR-34 family $(a, b, c)$, these miRNAs directly repress cell cycle and proliferation proteins such as cyclin E2, CDK4 and CDK6 (Figure 5) (He et al., 2007; Raver-Shapira et al., 2007). Cyclins and cyclin dependent kinases work together as cell cycle checkpoints, by repressing these checkpoint proteins the cell is unable to pass from one phase to another resulting in arrest. There are a number of other miRNAs that are involved in downstream p53 responses including miR-205, miR-215, miR-192 and miR- 
107 that aid in producing cell cycle arrest as well as miR-16 involved in apoptosis (Figure 5). Another set of miRNAs that are directly induced by p53 are miR145/miR143, a pair of miRNAs that are both produced from the CARMEN transcript (Sachdeva et al., 2009). miR-145 has direct effects on c-myc a known proto-oncogene. Both miR-143 and miR-145 are known to affect a more important target and that is MDM2 (Figure 6). These two miRNAs directly interact with MDM2, they are activated by p53 themselves where they feed back to inhibit MDM2, leading to increased activation of p53 in a feedforward system (Zhang et al., 2014). This is accomplished in a p53dependent manner, as mutated p53 when transfected with miR143/145 showed no effects on cell cycle and apoptosis. Additionally, the downregulation of these miRNAs in cancer cells allows for another mechanism to evade p53 tumor suppression.

p53 is capable of directly inducing miRNAs through transcription or by interacting with both Drosha and Dicer processing proteins. Maturation of; miR-15a, miT-16-1, miR-143, miR145, miR-199a and miR-122 are all regulated by p53 through interactions with Drosha (Figure 4) (Feng et al., 2011; Hermeking, 2012). In this case p53 interacts with the Drosha complex through the DEAD-box RNA helicase p68 (DDX5), facilitating the processing of pri-miRNA. In contrast, mutant p53 can inhibit Drosha processing by blocking association with p68, leading to reduced processing of specific miRNAs (Gurtner et al., 2016). Bridging between Drosha and pri-miRNA can be disrupted by mutant p53 through its binding of p72/82, the helicase that facilitates this connection (Garibaldi et al., 2016). Wild type p53 can indirectly regulate miRNA activity by inducing RNA-binding motif protein 38 that binds to the 3'UTR of mRNA and blocks miRNA association (Leveille et al., 2011). Further downstream the RISC complex and Dicer protein are not beyond the reach of wild type and mutant p53 (Figure 4). Where wild type p53 associates with AGO-2 and regulates the formation of RISC (Krell et al., 2015), mutant p53 reduces Dicer 
expression by repressing p63, a trans-activator that binds to the Dicer promoter (Muller et al., 2014).

More than 20 miRNAs have been reported to directly regulate p53 itself (Feng et al., 2011; Hermeking, 2012). The first two miRNAs that were found to directly regulate $\mathrm{p} 53$ were miR-125b and miR-504 (Le et al., 2009; Hu et al, 2010). These miRNAs bind to the 3'UTR of p53 and negatively regulate it, targeting p53 genes involved in apoptosis and cell cycle arrest (Yin et al., 2015). Since then a number of miRNAs have been found in different tissues to negatively regulate p53 directly including; miR-1285, miR-92, miR-16, miR-25, miR-15a, miR-19b and, miR-200a (Figure 6) (Hermeking, 2012; Deng \& Sui, 2013). All of these miRNAs suppress p53 expression and lead to decreased apoptosis, cellular senescence and aid in cell invasion and growth attributed to tumorigenesis. There are a host of miRNAs that also regulate p53 in an indirect way. This group includes; miR-143/145, miR-605, miR-25, miR-32, miR-18b and miR-449 (Figure 6) (Feng, 2011; Hermeking, 2012; Hoffman et al., 2014; Zhang et al, 2014). These miRNAs indirectly regulate p53 through repression of MDM2, in turn this relieves the inhibition of its expression and leads to activation. Other miRNAs such as; miR-34a, miR-661, miR-199a and miR-887 perform a similar function only targeting MDM4, a second important regulator of p53 (Hermeking, 2012; Hoffman et al., 2014). 


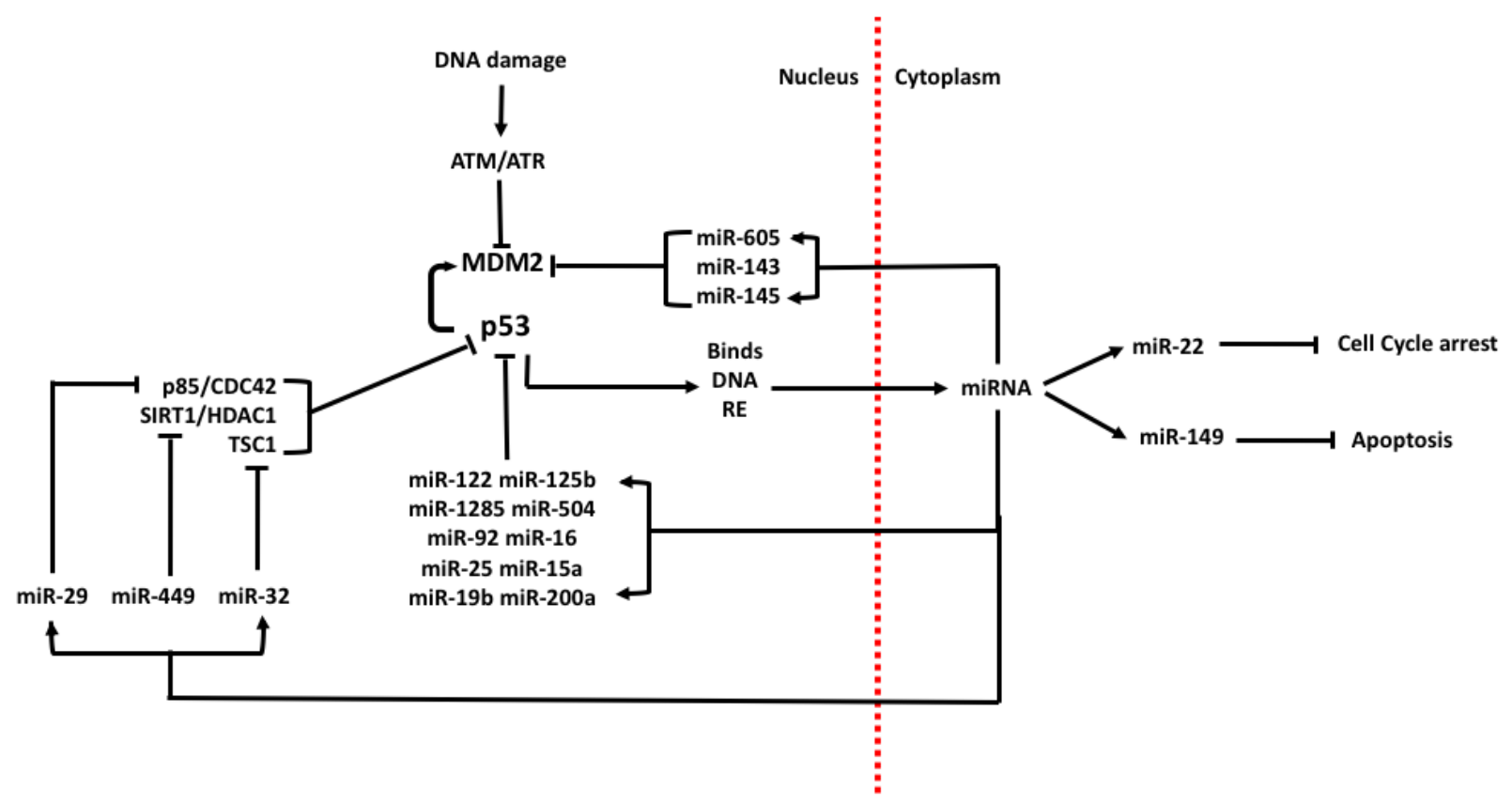

Figure 6. miRNA feedback control over the p53 response network. miRNAs are capable of regulating the p53 response through downstream components to change network effects and directly or indirectly regulate p53 expression through MDM2 and other proteins.

The interplay between miRNA activation by p53 and its subsequent regulation by a host of miRNAs leads to a large network, one with multiple feedback and feedforward pathways allowing cells to control this extremely important tumor suppressive network. It does, however, allow cancer cells to evade this internal control through manipulation of these interactions.

\subsection{Polyadenylation and 3'UTR}

Transferring genomic information into protein within the cell relies on the production of mRNAs as an intermediate. These RNA molecules undergo processing to compact and protect the message from degradation. The 3' untranslated region (3'UTR) of these transcripts has long been known to play a critical role in protecting mRNAs from degradation, along with playing a role in many regulatory mechanisms. The half-life, stability, and localization of the mRNA transcript is largely controlled by the 3'UTR. Within the 3'UTR are many regulatory elements for RNA 
binding proteins, translational machinery, and noncoding RNA with the length of the UTR effecting many properties of the transcript.

The many response elements within the UTR include both cis-acting elements and transacting elements (Matoulkova et al., 2012). Cis-acting elements are generally well conserved and consist of AU-rich elements, GU-rich elements, CU-rich elements, CA-rich elements and iron responsive elements (Matoulkova et al., 2012). The most common of these elements are AU-rich sequences, also known as (AREs), these influence mRNA stability, translation, and alternative splicing. A basic motif characterized as an AU-rich region is AUUUA and can exist in various repeats (Figure 6B). There are three classes of AREs; class I is the standard sequence, class II contains multiple copies acting together and class III is a GUUUG sequence termed a nonAUUUA. ARE binding proteins recognize these sequences and work as turnover and translation regulators. GU-rich elements are less prevalent than AU-rich elements with a similar sequence of GUUUG in 2-5 overlapping pentamers (Figure 7B), repetition does not affect mRNA decay effectiveness unlike AREs (Halees et al., 2011). Each of these elements work towards stabilizing mRNA transcripts and play a role in the translation and turnover of targets.

Trans-acting factors unlike cis-acting are not specific sequences but rather specific proteins or other molecules that regulate the transcript through the UTR. RNA binding proteins (RBPs) are a common form of trans-acting factors that recognize cis-acting regions (Figure 6B). The p53 protein itself can act as an RBP along with its downstream target p21, outside of RBPs other transacting factors are non-coding RNA. Seed regions for non-coding RNA are located in both the 5'UTR and the 3'UTR but predominantly these sequences are found in the 3'UTR. Throughout the entire genome on average a gene is likely to contain 17-80 miRNA binding sites (MBEs) which are predominantly found within the 3'UTR (Helwak \& Tollervey, 2014; Agarwal et al., 2015). 
miRNAs dominate this category, however long noncoding RNAs are also contributors to regulation of mRNAs.

MDM2 contains an abnormal 3'UTR as it is $\sim 7 \mathrm{~kb}$ in total length, this is a considerably long 3'UTR for a transcript as the genome wide average is $0.8 \mathrm{~kb}$ (Mignone et al., 2002). Within this 3'UTR there are a host of regulatory elements. There are an estimated 760 miRNA binding sites within the 3'UTR of MDM2, the majority of these sites are likely non-functional, however, this prediction shows the implications a long 3'UTR can have (Lewis et al., 2005). Along with many potential and putative miRNA targets there are potential Alu elements within the MDM2 3'UTR. These transposable elements have implications in miRNA function. Growing evidence suggest some miRNAs may by derived from TEs and more specifically Alu elements (Smalheiser \& Torvik, 2005; Piriyapongsa et al., 2007; Yuan et al., 2010; Dahary et al., 2011). Not only can they be derived from these elements but they may also provide additional miRNA binding sites throughout the genome (Hoffman et al., 2014; Smalheiser \& Torvik, 2006). This abnormal 3'UTR contains many AREs spread throughout that also add to the regulatory network of MDM2. One mechanism that heavily effects the regulatory ability of these 3'UTR elements is polyadenylation and the use of alternative sites.

The correlation of genotype to phenotype is strongly affected by gene expression, including both splicing and alternative polyadenylation. There are two main sequences required for polyadenylation machinery; a consensus hexanucleotide signal (AAUAAA) around 20-40bp upstream of a cleavage site and, a variable GU rich element located within 50 nucleotides downstream (Figure 7A) (Shi \& Manley, 2015). APA is an important process as 70\% of human genes express mRNAs with different 3' ends due to this process (Wang et al., 2008; Tian et al., 
2005; Derti et al., 2012). Alternative splicing combined with an intronic APA can also produce dramatically different carboxy termini, affecting protein structure and function.
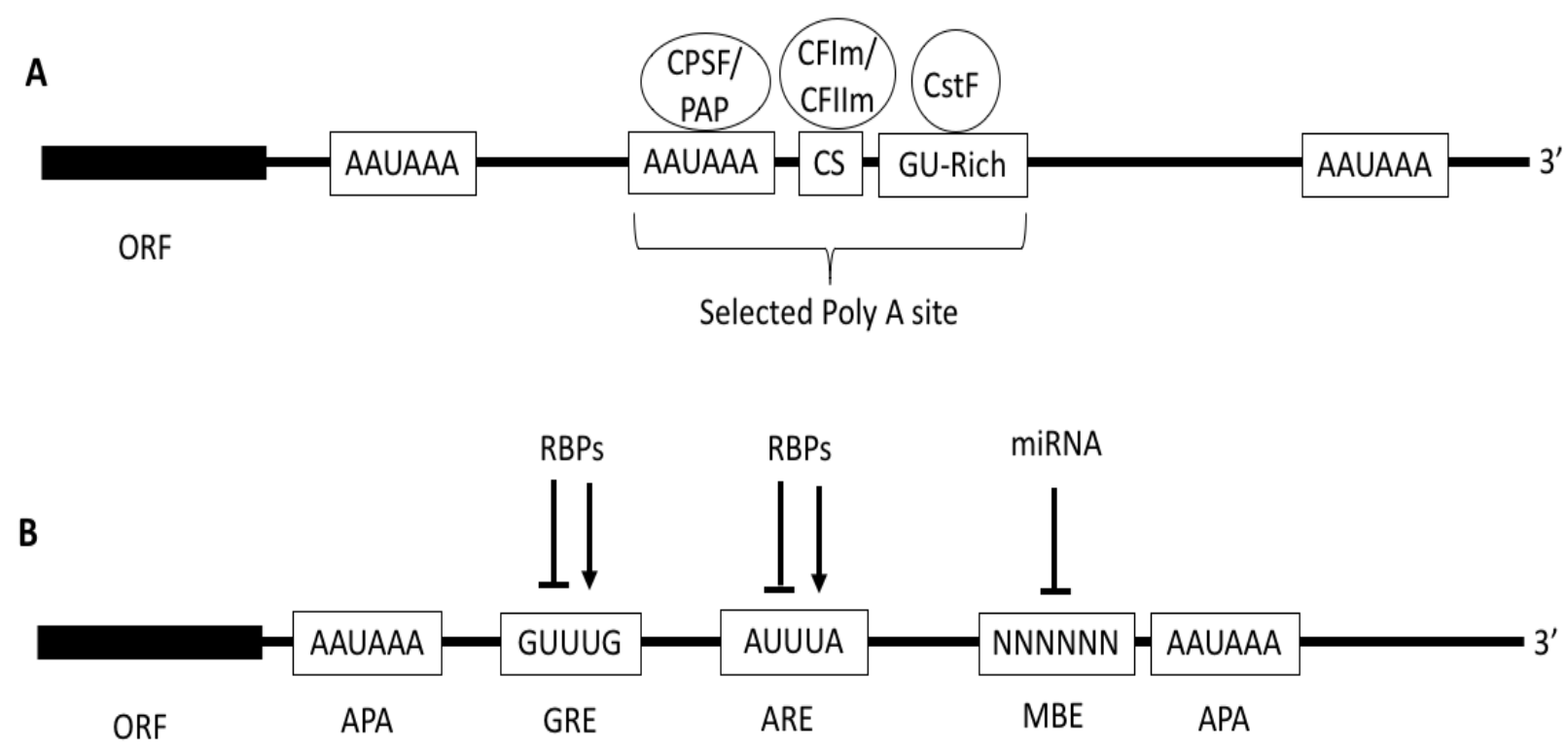

Figure 7. Poly A site elements and binding factors involved in cleavage of the 3'UTR (A). Multiple poly A sites are spread throughout the 3'UTR, once a site is chosen cleavage and polyadenylation stimulating factor (CPSF) binds the upstream AAUAAA sequence recruiting poly a polymerase (PAP), cleavage factors I and IIm (CF) bind the cleavage site and cleavage stimulating factor $(\mathrm{CstF})$ binds the downstream $\mathrm{GU}$ rich region. Cis and trans acting factors that regulate transcripts using the 3'UTR (B). RNA binding proteins (RBPs) bind to GREs and AREs, miRNA binding sites (MBE) are scattered throughout the 3'UTR along with alternative polyadenylation sites (APA).

Genetic variation drives these changes resulting in differences of phenotype from inclusion to exclusion of important motifs. A simple polymorphism producing a single-nucleotide substitution in the AAUAAA hexanucleotide signal can reduce the efficiency of 3' end formation by up to $70 \%$ (Sheets et al., 1990). Genetic alteration of these key sequences are major risk factors in perpetuating a host of diseases.

The length of every transcript is governed by polyadenylation, the endonucleolytic cleavage of RNA by polyadenylation machinery and the subsequent polyadenylation by poly(A) polymerase (PAP) (Proudfoot, 1991; Colgan \& Manley, 1997). Processing by polyadenylation produces transcripts of varying lengths depending on where the poly A site is located. Signal 
sequences aiding in the recognition of poly A sites are strongly conserved among mammals with the canonical sequence being AAUAAA, although varying sequences are used within the genome (Derti et al., 2012).

Recognition of a poly A site relies on both the upstream signal sequence and a downstream U-/UG- rich region that help to position the poly A machinery (Figure 7A and 8A) (Millevoi \& Vagner, 2010; Tian \& Graber, 2012). These downstream regions are not always present and also differ in sequence however, both elements are used in the coordinated cleavage to some extent. This coordinated cleavage utilizes multiple components including; cleavage and polyadenylation stimulating factor (CPSF), cleavage stimulating factor (CstF), and, cleavage factors Im and IIm (CFIm, CFIIm) (Figure 8A). Additionally, poly A binding proteins stimulate PAP in catalyzing the addition of untemplated adenosines regulating the length of the poly A tail (Kuhn et al., 2009).

A

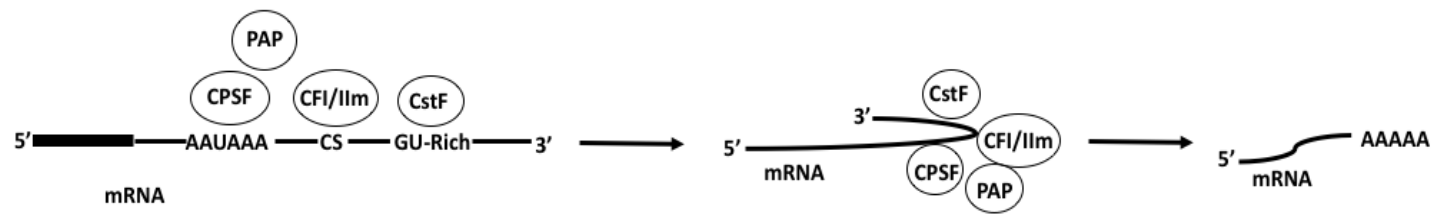

B

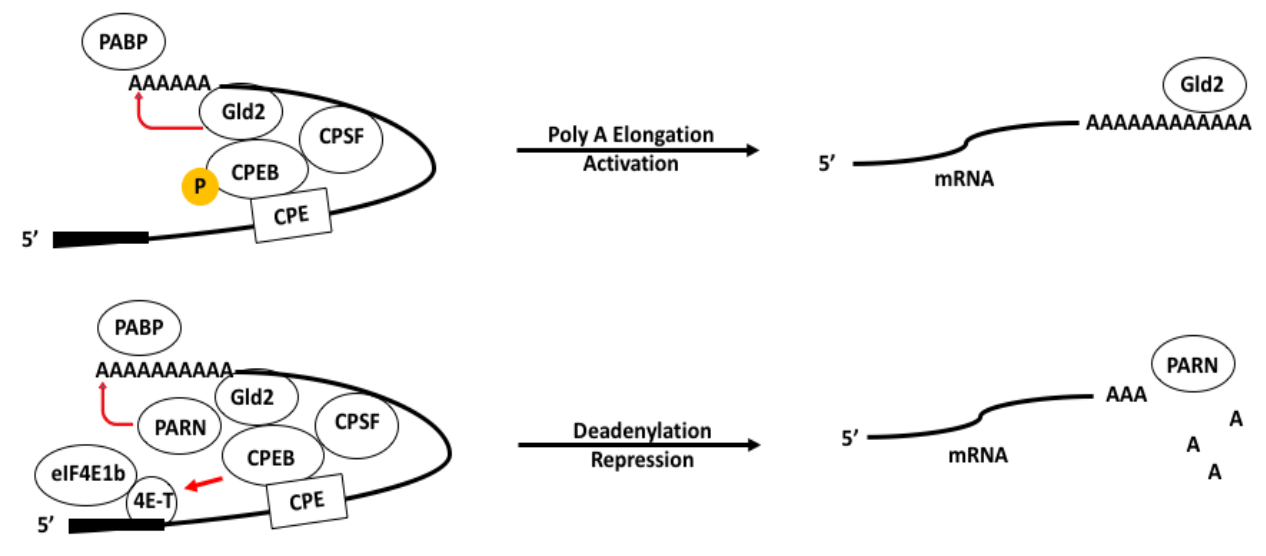

Figure 8. Canonical cleavage of a poly A site performed in the nucleus (A). Cytoplasmic polyadenylation is used for repression or activation of translation depending on the process used. Phosphorylation of CPEB binding protein regulates which process is used, phosphorylation activates Gld2 elongation of the poly A increasing translation (B) and dephosphorylation recruits PARN leading to de-adenylation or repression of translation binding false 5' cap binding isoforms 4E-T and EIF4E-1b (C). 
Use of varying signal sequences and poly A sites produces populations of mRNA transcripts that differ in length, and is termed alternative polyadenylation (APA). The alternate polyadenylation of pre-mRNA produces isoforms that differ in length depending on the site that is used, changing the cis-regulatory elements present. In fact, a genome wide analysis showed that $70 \%$ of known human genes have multiple poly A sites located within their UTR and that usage of sites is tissue-specific (Derti et al., 2012; Tian et al., 2005). APA is a critical component of cellular regulation as global 3'UTR lengthening is significantly associated with embryonic development in mice (Ji et al., 2009; Kleppe et al., 2012; Velten et al., 2015). On the other side 3'UTR shortening is associated with activated T-cell proliferation (Sandberg et al., 2008). With regulatory elements scattered throughout the 3'UTR, the length of the distal region of a transcript can play a major role in its stability and regulation. Binding sites for miRNAs are predominantly found within the 3'UTR of an mRNA. Therefore, the number and positioning of miRNA binding sites are affected by the specific poly A site used. Complex interplay between miRNA functionality and alternative polyadenylation appears to exist in a cell and gene specific manner.

The regulation of 3'UTR length and APA has not been fully elucidated however, it has been linked to components of the cleavage machinery. Both CstF2 and CFIIm have been linked to the production of varying UTR lengths. Upregulation/downregulation of these factors led to either distal or proximal cleavage of mRNAs that appeared to be dependent on the cell type (Akman et al., 2015; Elkon et al., 2012; Gruber et al., 2012; Martin et al., 2012; Masamha et al., 2014). Although these factors have been linked to APA site selection, the conditions in which they induce these changes has yet to be revealed. APA and polyadenylation in general do occur cotranscriptionally and may coordinate with transcriptional machinery in the selection of cleavage sites. Protection of mRNAs from degradation in the cytoplasm is an important processing event 
that occurs within the nucleus before shuttling into the cytoplasm for translation. The role of polyadenylation makes this process predominantly a nuclear event, however there is emerging evidence that cytoplasmic polyadenylation is possible.

There are many roles played by polyadenylation of mRNAs, APA site usage determines mRNA transcript length affecting regulatory elements, stability and in some cases localization. Cytoplasmic polyadenylation mainly plays a role in translational activity of mRNAs. This involves a number of factors targeting the 3'UTR that can act on translational activation, repressors and, de-adenylation of mRNAs (Figure 8B\&C) (De Moor \& Richter, 1999; Huarte et al., 1992). In all cases, cytoplasmic polyadenylation uses the same signal as nuclear polyadenylation (Wang et al., 2008; Charlesworth et al., 2006; McGrew \& Richter, 1990; Vishnu et al., 2011; Simon et al., 1992). The majority of research on cytoplasmic polyadenylation comes from embryo studies, as the mRNA regulated by this process are predominantly involved in mitosis and meiosis in early stages.

Specific machinery is recruited to mRNAs in the cytoplasm with the best known cytoplasmic poly A polymerase being PAPd4 (Gld2) (Wang et al., 2002; Kwak et al., 2004). Recruitment of factors involves binding of CPEB proteins to the cytoplasmic polyadenylation element (CPE) in the 3'UTR (Figure 8B\&C). CPE elements are U-rich regions typically with sequences of UUUUAU or UUUUAAU (Hake \& Richter, 1994; McGrew \& Richter, 1990; Sheets et al., 1994). Typically, elongation of the poly A tail involves phosphorylation of CPEB, preventing binding and interactions with 5' cap binding proteins and PARN. This allows for activation of Gld 2 and poly A elongation, sometimes to upwards of 100 adenosine residues (Figure 8B). Dephosphorylation then allows for CPEB to recruit PARN blocking Gld2 activity and reducing the poly A tail (Figure $8 \mathrm{C}$ ). Likewise binding to false 5'cap protein isoforms $4 \mathrm{E}-\mathrm{T}$ and EIF2E-1b inhibits translational machinery from binding. Location proximity relative to other 
CPE's or response elements can dictate whether these sites are activators or repressors (Pique et al., 2008).

Interaction between CPEB proteins and TP53 play a role in senescence and bypass of this cell cycle arrest in cancers (Burns \& Richter, 2008). The reduced polyadenylation of TP53 due to downregulated CPEB-1 allows for decreased TP53 translation. In turn bypassing its response pathway that regulates senescence in rapidly proliferating cancer cells. In this system the noncanonical PAP, Gld2 regulates miR-122 stability through mono-adenylation of its 3'UTR, miR-122 then down regulates CPEB-1 expression leading to reduced polyadenylation of TP53 (Burns et al., 2011; D’Ambrogio et al., 2012; Katoh et al., 2009). This system along with other CPEB interactions are just a small factor that allow cancer cells the advantage of bypassing internal controls such as p53 tumor suppression.

\section{8 p53 protein and 3' END Processing}

The 3'UTR undergoes many changes and contains many regulatory elements, it is no surprise that p53 can also target the 3'UTR for regulation and is itself regulated through its own UTR. Another feedback loop present in the p53 network involves 3'UTR interactions with the protein PARN de-adenylase. De-adenylation of a transcript by PARN reduces its stability and, therefore, its half-life within a cell. Multiple interactions have been reported between p53 and PARN, under normal non-stress conditions PARN reduces the poly A tail length of p53, destabilizing it and aiding in maintaining below threshold, non-stress levels (Figure 9). Knockdown of PARN in fact, can lead to an apoptotic response similar to that of UV exposure to the cell (Devany et al., 2013). This is accomplished in a transactivation independent manner, as an ARE element in the C-terminal of p53 interacts with the C-terminal of PARN (Devany et al., 2013). 


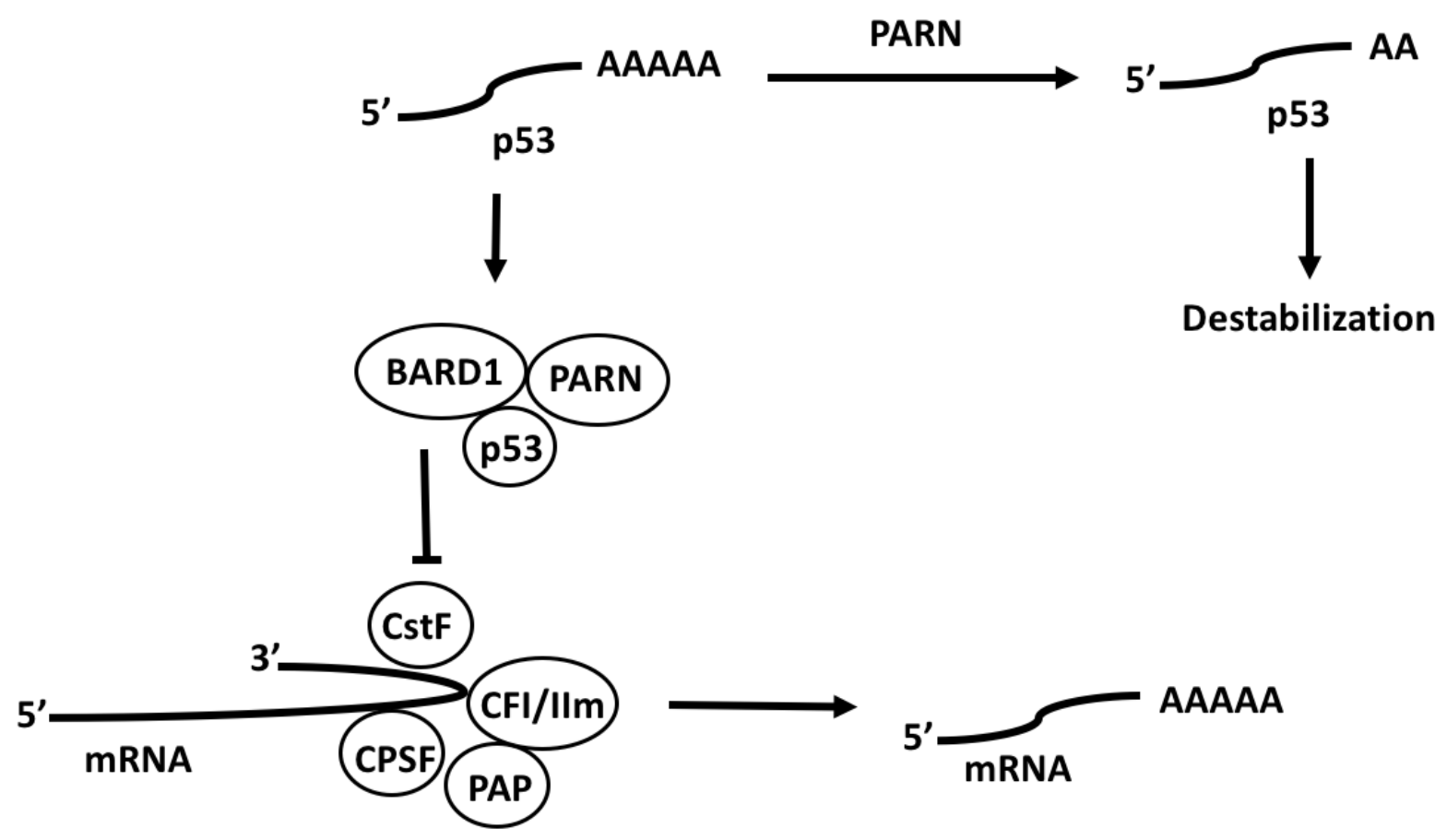

Figure 9. Regulation of p53 using 3' end processing and its involvement in 3' end processing of other mRNAs. PARN deadenylase binds to an ARE in the 3'UTR of p53 leading to shortening of its poly A and destabilization. p53 also associates with PARN and BARD1 creating a complex with CstF and inhibiting 3'end processing.

p53 also uses association with the PARN/CstF/BARD1 complex to regulate mRNA posttranscriptionally. This complex regulates 3' cleavage and polyadenylation, altering the length of mRNA transcripts in the downstream p53 response (Devany et al., 2013). BARD1 is a common gene mutated in breast cancer and CstF is a primary cleavage stimulating factor in polyadenylation, both are known to interact with each other along with p53 leading to the repression of 3' cleavage (Figure 7) (Nazeer et al., 2011). When p53 is activated by DNA damage this complex is stabilized by the association of p53, during stress conditions this could lead to the degradation of prematurely terminated transcripts. The inhibition of 3'UTR processing has been reported to vary with p53 expression as p53 induced different 3' processing profiles (Singh et al., 2009). These findings indicated a cell specific and p53 dependent change in 3' end processing involved in tumor suppression. 


\subsection{Rationale}

Recent work in our lab (Cabrita et al., 2016), examined the relationship between p53 activation and expression of miRNAs and mRNAs using a cell line expressing a temperature sensitive variant of p53. Using microarray and qRT-PCR analysis, the expression of various p53 regulated miRNAs and mRNAs were analyzed over an extended period of time.

The expression of p53-regulated mRNAs like MDM2 increased within hours and remained elevated up to 48 hours at the permissive temperature (Cabrita et al, 2016). Similarly, p53responive miRNAs, including miR-34a, miR-143 and miR-145, were simultaneously induced to high levels. As miR-143 and miR-145 target MDM2, we had anticipated that MDM2 levels would eventually decrease as these miRNAs silenced MDM2. However, there was no evidence of this form of miRNA-mediated feedback. Given the relationship between mRNAs and miRNA mediated inhibition, it was surprising to note sustained elevated mRNA levels in the presence of elevated inhibitory miRNAs. This led to the question of how the p53 response would act when allowed to recover.

When cells were returned to the restrictive temperature, mRNAs decayed rapidly returning to basal levels within hours, while the co-expressed miRNAs were stably expressed, remaining elevated for days in the absence of functional p53 (Cabrita et al, 2017). The difference in stability of these classes of p53-regulated RNAs led to high miRNA but low p53-regulated mRNA levels following recovery. This disequilibrium prompted our lab to determine if cells were capable of mounting a second p53 response in the presence of pre-existing inhibitory miRNAs.

Therefore, cells were placed at the permissive temperature, returned to the restrictive temperature and again incubated at the permissive temperature to activate p53 a second time (Cabrita et al, 2017). Under these conditions, a subset of p53-induced mRNAs including MDM2 
were not induced as strongly during the second response (Cabrita et al., 2017). The affected transcripts were predicted targets of p53-regulated miRNAs (miR-34A, miR-143 and miR-145). This suggested that miRNAs may in fact play a role in modulating the p53 response under specific conditions (Figure 10).

In the present work, we sought to genetically test the role of miRNAs in modulating the p53 response using nutlin-3A as a reversible activator of the p53 response. HCT116 cells express wildtype p53 and we were able to obtain isogenic miRNA processing defective cell lines with targeted deletions of the DROSHA and DICER genes.

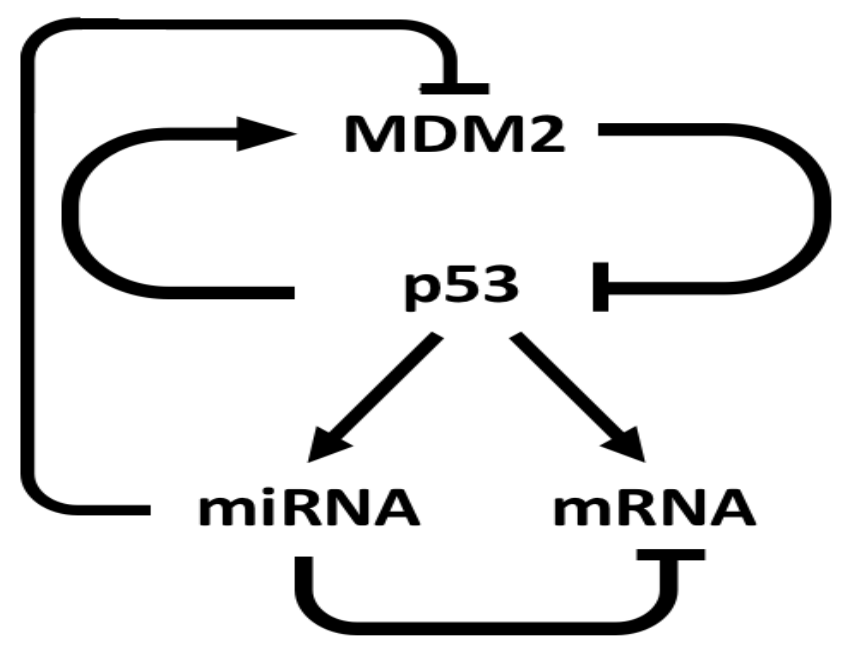

Figure 10. p53-MDM2 feedback loop and suggested interactions of miRNA control over the network. 


\subsection{Objective}

The objective of this study was to assess the role miRNAs play in modulating the p53 response, using the competitive MDM2 inhibitor nutlin-3A to activate p53. We used the p53expressing HCT116 human colon cancer cell line and two isogenic sublines with targeted disruption of the DROSHA and DICER genes to genetically test the role of miRNAs on the p53 response. It was the goal of this study to determine if miRNAs play a role in the selective attenuation of specific p53-regulated mRNAs like MDM2, and by what mechanism they affect this response. 


\section{Methods}

\subsection{Cell Culture}

HCT116 parental p53 expressing cells and CRISPR Cas9 HCT116 Parental, Drosha ${ }^{-/-}$and Dicer $^{-/}$cells were used for tissue culture experiments. HCT116 cells were obtained from the American Tissue Culture Collection (ATCC). Isogenic derivatives of HCT116 cells with CRIPSR Cas9 targeted deletion of DROSHA and DICER genes were obtained from the Korean Collection for Type Cultures (KCTC)(Kim et al., 2016). All cell lines were grown in McCoy's 5A media (Hyclone, Logan, UT) supplemented with 1X penicillin/streptomycin (Hyclone, Ottawa, ON), 3\% fetal bovine serum (Gibco, Mississauga, $\mathrm{ON}$ ) and, 10\% new born calf serum (Gibco, Mississauga, ON). All cultures were kept in an incubator at $37^{\circ} \mathrm{C}, 100 \%$ humidity and, $5 \% \mathrm{CO}_{2}$.

\subsection{Drug Treatment}

Cell cultures were treated with $10 \mu \mathrm{M}$ nutlin-3A (Sigma-Aldrich, St.Louis, Mo), diluted from stock to $1 \mathrm{mM}$ in DMSO and working stocks of $0.1 \mathrm{mM}$ in phosphate buffered saline (PBS). Treatment media was made with 9mL of McCoy's 5A media mixed with $1 \mathrm{~mL}$ of $0.1 \mathrm{mM}$ nutlin3A in PBS. Cells were seeded 24hrs prior to experiments and incubated overnight. Treatment protocol consisted of $24 \mathrm{hrs}$ incubation with $10 \mu \mathrm{M}$ nutlin-3A media, dishes were rinsed twice with PBS then incubated for $6 \mathrm{hrs}$ in non-treated media followed by $24 \mathrm{hr}$ incubation in $10 \mu \mathrm{M}$ nutlin-3A media.

\subsection{RNA Isolation}

Total RNA including miRNAs from cultured cells was purified using the mirVana miRNA isolation kit (Invitrogen, Fisher Scientific Ltd. Ottawa, ON) as described by the manufacturer. 


\section{2 microRNA Reverse Transcription (RT)}

Samples were quantified using a DeNovix DS-11 Spectrophotometer (DeNovix, Wilmington, DE). Equal amounts of RNA were reverse transcribed using a TaqMan ${ }^{\circledR}$ MicroRNA Reverse Transcription Kit (Applied Biosystems, Fisher Scientific Ltd., Ottawa, ON) and a GeneAmp PCR System 9700 (Applied Biosystems, Fisher Scientific Ltd., Ottawa, ON) as described by the manufacturer. Primers used were TaqMan ${ }^{\circledR}$ 5X RT Gene Expression Assays primers for miR-103, miR-34a-5p, miR-143-3p, and miR-145-5p.

\section{3 miRNA Quantitative Reverse Transcriptase Polymerize Chain Reaction (qRT-PCR)}

qRT-PCR was completed using the StepOnePlus Real-Time System with StepOne Software v2.3 (Applied Biosystems, Fisher Scientific Ltd., Ottawa, ON). Reaction consisted of $10 \mu$ L TaqMan® Universal Master Mix II, with UNG (Applied Biosystems, Fisher Scientific Ltd., Ottawa, ON), $1 \mu \mathrm{L}$ TaqMan® 20X TM Gene Expression Assays primer (miR-103, miR-34a-5p, miR-143-3p, and miR-145-5p), 7.67 $\mu \mathrm{L}$ RNAse free water, and $1.33 \mu \mathrm{L}$ of the appropriate sample. Reaction tubes were vortexed briefly then placed in the StepOnePlus Real-Time PCR System, and were cycled at $50^{\circ} \mathrm{C}$ for 2 minutes, $95^{\circ} \mathrm{C}$ for 10 minutes, and then underwent 50 cycles comprised of $95^{\circ} \mathrm{C}$ for 15 seconds followed by $60^{\circ} \mathrm{C}$ for 1 minute.

\section{2 mRNA Reverse Transcription (RT)}

Samples were quantified using a DeNovix DS-11 Spectrophotometer (DeNovix, Wilmington, DE). Equal amounts of RNA were reverse transcribed using the High Capacity cDNA Reverse Transcription Kit (Applied Biosystems, Fisher Scientific Ltd., Ottawa, ON) and a GeneAmp PCR System 9700 (Applied Biosystems, Fisher Scientific Ltd., Ottawa, ON) as described by the manufacturer. Samples were reverse transcribed using either random primers 
(Applied Biosystems, Fisher Scientific Ltd., Ottawa, ON) or oligo-dT primers (Integrated DNA Technologies Inc.), as indicated in the results text.

\section{3 mRNA Quantitative Reverse Transcriptase Polymerize Chain Reaction (qRT-PCR)}

qRT-PCR was completed using the StepOnePlus Real-Time System with StepOne Software v2.3 (Applied Biosystems, Fisher Scientific Ltd., Ottawa, ON). For Taqman qRT-PCR the reaction consisted of $10 \mu \mathrm{L}$ TaqMan ${ }^{\circledR}$ Universal Master Mix II, with UNG (Applied Biosystems, Fisher Scientific Ltd., Ottawa, ON), $1 \mu \mathrm{L}$ TaqMan® Gene Expression Assays primer (MDM2, CDKN1A, GAPDH), and $9 \mu \mathrm{L}$ of the appropriate sample. Reaction tubes were vortexed briefly then placed in the StepOnePlus Real-Time PCR System, and were cycled at $50^{\circ} \mathrm{C}$ for 2 minutes, $95^{\circ} \mathrm{C}$ for 10 minutes, and then underwent 50 cycles comprised of $95^{\circ} \mathrm{C}$ for 15 seconds followed by $60^{\circ} \mathrm{C}$ for 1 minute.

SYBR green qRT-PCR reactions consisted of either $10 \mu \mathrm{L}$ PowerUp ${ }^{\mathrm{TM}}$ SYBR Green Master Mix (Applied Biosystems, Fisher Scientific Ltd., Ottawa, ON) or $10 \mu \mathrm{L}$ SensiFASTтм SYBR Hi-ROX (BioLine, FroggaBio Inc., Toronto, ON), $4.2 \mu \mathrm{L}$ RNAse free water, $4.2 \mu \mathrm{L}$ cDNA sample and $0.8 \mu \mathrm{L}$ Forward $/ 0.8 \mu \mathrm{L}$ Reverse primer (see primer list for information). Annealing temperatures were run at least $5^{\circ} \mathrm{C}$ below $\mathrm{Tm}$. For $\mathrm{Tm} 60^{\circ} \mathrm{C}$ and above samples were run for 5 mins at $50^{\circ} \mathrm{C}, 2 \mathrm{mins}$ at $95^{\circ} \mathrm{C}$ then cycled from $40-60$ cycles at $95^{\circ} \mathrm{C}$ for $15 \mathrm{sec}$ and annealing temperature for $30 \mathrm{sec}$. For $\mathrm{Tm}$ below $60^{\circ} \mathrm{C}$ samples were run for $5 \mathrm{mins}$ at $50^{\circ} \mathrm{C}, 2 \mathrm{mins}$ at $95^{\circ} \mathrm{C}$ then cycled from $40-60$ cycles at $95^{\circ} \mathrm{C}$ for $15 \mathrm{sec}$, annealing temperature for $15 \mathrm{sec}$ and then extended at $72^{\circ} \mathrm{C}$ for $1 \mathrm{~min}$.

\subsection{3'Rapid amplification of cDNA ends (3'RACE)}

Equal amounts of RNA were reverse transcribed using the High Capacity cDNA Reverse Transcription Kit (Applied Biosystems, Fisher Scientific Ltd., Ottawa, ON) and a GeneAmp PCR 
System 9700 (Applied Biosystems, Fisher Scientific Ltd., Ottawa, ON) as described by the manufacturer with the exception of the primers. RNA was reverse transcribed using oligo-dT primers (Integrated DNA Technologies Inc.), rapid amplification of cDNA ends was done running samples with $5 \mu \mathrm{L}$ RT buffer (Applied Biosystems High capacity kit) $0.5 \mu \mathrm{L}$ Taq polymerase, $1 \mu \mathrm{L}$ dNTP, $2 \mu \mathrm{L}$ anchored oligo-dT primer with linker diluted to $10 \mu \mathrm{M}$ in TAE (Integrated DNA Technologies Inc.) and equal amounts of cDNA mixed with RNAse free water. Samples were run in a GeneAmp PCR System 9700 (Applied Biosystems, Fisher Scientific Ltd., Ottawa, ON) for 5 mins $98^{\circ} \mathrm{C}, 2$ mins $47^{\circ} \mathrm{C}, 5 \operatorname{mins} 72^{\circ} \mathrm{C}$ followed by 60 cycles of $94^{\circ} \mathrm{C} 15 \mathrm{sec}, 47^{\circ} \mathrm{C} 30 \mathrm{sec}$ and $72^{\circ} \mathrm{C}$ 3 mins with a final elongation of $72^{\circ} \mathrm{C}$ for 7 mins. RACE samples were then analyzed using the StepOnePlus Real-Time System with StepOne Software v2.3 (Applied Biosystems, Fisher Scientific Ltd., Ottawa, ON) and SYBR green conditions with UTR forward primers and linker primer as the reverse for all samples diluted to $10 \mu \mathrm{M}$ in TAE (Integrated DNA Technologies Inc.).

\subsection{DNA Gel purification and Sequencing}

Samples from 3'RACE and random primers were saved following qRT-PCR and processed for sequencing. First PCR products were purified using the QIAquick PCR purification kit (QIAGEN Inc. Toronto, ON) as described by the manufacturer. Purified products were sent for sequencing to StemCore Laboratories at the Ottawa Hospital Research Institute.

PCR products were also gel purified with bands extracted and sent for sequencing. First samples were separated on a $2 \%$ agarose gel made with TAE and $0.25 \mu \mathrm{g} / \mathrm{ml}$ ethidium bromide (BIORAD), equal amounts of sample were combined with gel loading buffer II (Invitrogen, Fisher Scientific Ltd., Ottawa, ON). Gels were imaged using a protein simple imager (Biotechne, California) with Alpha Imager HP software. Bands were excised over a transilluminator and 
purified using a gel extraction miniprep kit (BS354, Biobasics Inc.) as described by the manufacturer and sent to StemCore Laboratories for sequencing.

Table 1. SYBR Green forward and reverse primers used for qRT-PCR and 3'RACE.

\begin{tabular}{|r|r|r|}
\hline \multicolumn{3}{|c|}{ Sigma-Aldrich } \\
\hline mRNA & Forward & Reverse \\
\hline Actin & GGGCATGGGTCAGAAGGAT & GTGGCCATCTCTTGCTCGA \\
\hline GAPDH & AGCCACATCGCTCAGACA & GCCCAATACGACCAAATC \\
\hline MDM2 & CCATGATCTACAGGAACTTGGTAGTA & TCACATCACAGATGTACCTGAGTCC \\
\hline \multicolumn{2}{|c|}{ Integrated DNA Technologies Inc. } \\
\hline mRNA & Forward & Reverse \\
\hline GAPDH & AGTCCCTGCCACACTCAGTC & TACATGACAAGGTGCGGCTC \\
\hline UTR (1) & AGTGAGAAAATGCCTCAATTCACA & GGAGTTGGTGTAAAGGATGAGC \\
\hline $\begin{array}{c}\text { UTR (2) } \\
\text { UTR (3) }\end{array}$ & ATGACAGGGTCAGCATGTGG & CCTGCAACAGGGGTCAAGAT \\
\hline $\begin{array}{c}\text { UTR (4) } \\
\text { UTR (5) }\end{array}$ & TGGCCAAAGGGATTAGTAGTTT & AAAATAGCTGTCACTGCCTCC \\
\hline $\begin{array}{c}\text { Proximal } \\
\text { Poly A }\end{array}$ & CCTTTACACCAACTCCTAATTT & AAATCTTTCACACATTTTCTCTT \\
\hline $\begin{array}{c}\text { Common } \\
\text { Poly A }\end{array}$ & TCAATTTGGAGTTGATAATATTTCA & AAATAATTGCATTCTTGAAACAATT \\
\hline $\begin{array}{c}\text { Distal } \\
\text { Poly A }\end{array}$ & TAGTGTGTAGGTCTGTAGG & CAGGCTGCCATGTGACCTAA \\
\hline 3' RACE & GACACATCTGCTTGCTTTACG \\
\hline Linker & \multicolumn{2}{|c|}{ GCAGCCCTCTGTACTTTAACA } \\
\hline
\end{tabular}

\subsection{Protein Quantification}

Cultured cells were centrifuged at $22^{\circ} \mathrm{C}$ and 1000rpm for 5 minutes in a Sorvall ST16R centrifuge (Thermo Scientific). Cell pellets were lysed in RIP A buffer at $4^{0} \mathrm{C}$ for 20 minutes followed by centrifugation for 20 minutes at $1275 \mathrm{rpm}$ in a Microfuge 22R centrifuge (Beckman Coulter). Total protein concentration of each lysate was determined in relation to bovine serum albumin (BSA) protein standards, absorbance readings were obtained with an iMARK micro plate 
reader (BIORAD) and MPM6 software. Protein concentrations were calculated using the BSA standard curve.

\subsection{Immunoblot Analysis}

Protein samples were prepared for gel electrophoresis with distilled water, 4X NuPAGE LDS sample buffer (1/4 of final sample volume; Life Technologies) and 10X reducing agent containing dichlorodiphenyltrichloroethane (1/10 of final sample volume; Life Technologies). Samples were heated at $70^{\circ} \mathrm{C}$ for 10 minutes and resolved alongside ladder marker Precision Plus Dual Color (BioRad) using precast NuPAGE 4-12\% Bis-Tris gels (Life Technologies) and 1X MOPS-SDS running buffer (50 mM MES, $50 \mathrm{mM}$ Tris Base, 0.1\% SDS, 1 mM EDTA, pH 7.3; Life Technologies). Proteins were transferred to a nitrocellulose membrane using 1X NuPAGE transfer buffer (Life Technologies) and stained with Ponceau S (1.3mg/mL Ponceau S, 1\% acetic acid). Membranes were then blocked with 5\% milk-TBST (50mM Tris, $150 \mathrm{mM} \mathrm{NaCl}(\mathrm{pH} 7.6)$ (TBS), 5\% milk powder, 0.1\% Tween20). Target proteins p53, MDM2 and CDKN1A (p21) were detected using primary antibodies; mouse anti-p53 (FLP 393 sc-6243; Santa Cruz Biotechnology), mouse anti-MDM2 (SMP14 sc-965; Santa Cruz Biotechnology) and mouse-anti p21 (Ab-1; CALBIOCHEM) respectively at 1:250 in 0.5\% milk-TBST. Primary antibodies were detected with horseradish peroxidase-conjugated goat-anti mouse secondary (m-IgGk BP-HRP; Santa Cruz Biotechnology) at 1:12000 in TBST. Proteins were visualized using Super Signal West Pico Chemiluminescent Substrate (Thermo Fisher Scientific) and imaged using a Fusion FX-5XT imager and VisionCapt programming (Vilber Lourmat). 


\section{Results}

\subsection{Absence of miRNA feedback in response to long term nutlin-3A exposure}

There are a variety of models for p53 activation. The MDM2 inhibitor nutlin-3A is one very effective method as it blocks the binding pocket of MDM2, competitively inhibiting the p53MDM2 feedback loop (Figure 1). Therefore, nutlin-3A leads to decreased p53 degradation and the accumulation of the protein and downstream targets including MDM2 and CDKN1A. We used the Taqman probe set to perform qRT-PCR of MDM2, CDKN1A and GAPDH expression. We detected an increase in MDM2 and CDKN1A expression when nutlin-3A was added to HCT116 human colon cancer cells (Figure 11A). Long-term incubation of cells led to the rapid and sustained accumulation of these transcripts. This indicates that nutlin-3A is both effective at inducing a p53 response, and that the p53 response itself is sustainable over long periods without obvious feedback regulation.

p53 activates a wide range of mRNAs while regulating a similarly large population of miRNAs. Previous work in our laboratory identified several strongly induced miRNAs that may regulate CDKN1A and MDM2 expression (Cabrita et al., 2016). Although these miRNAs appear to follow a similar pattern to mRNAs, there were no statistically significant changes in expression levels over the $48 \mathrm{hr}$ treatment (Figure 11B). This did not indicate a clear p53 response from target miRNAs, different from the significant changes observed in our previous temperature sensitive model (Cabrita et al., 2017). 

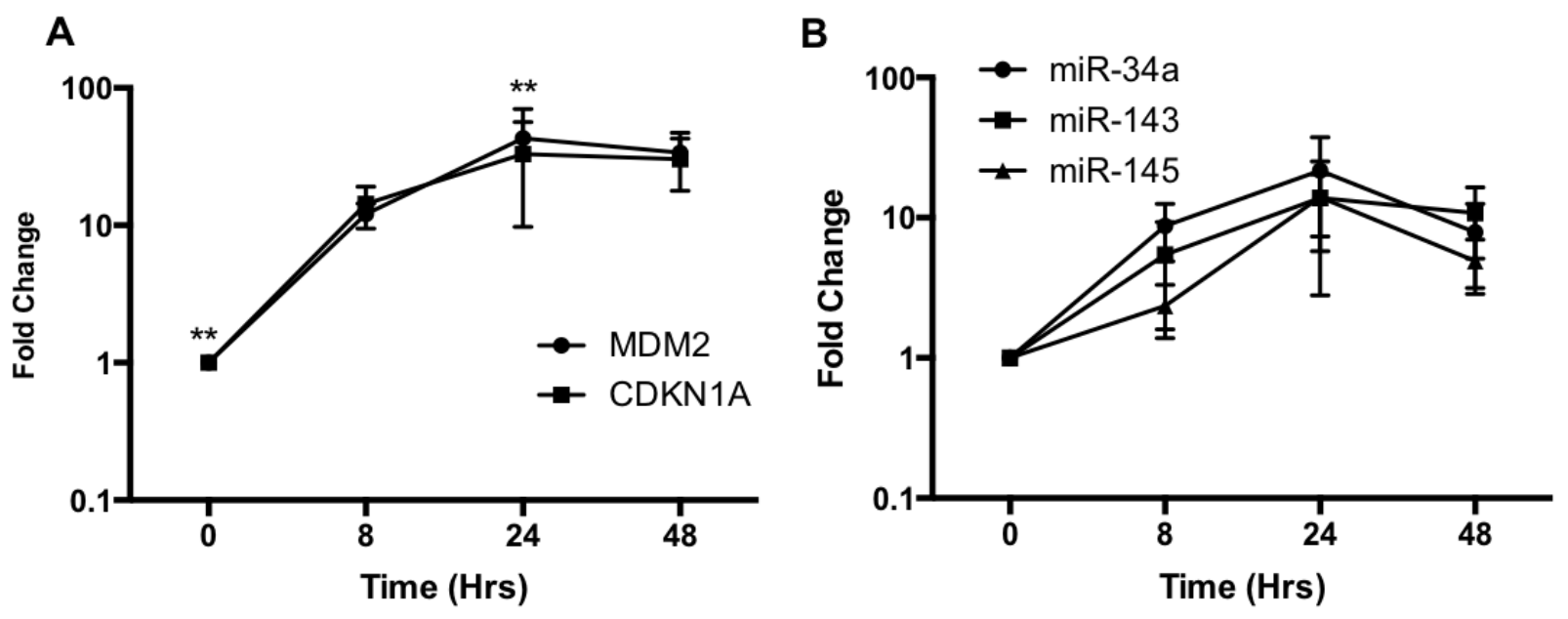

Figure 11. Fold change of p53-responsive MDM2 and CDKN1A mRNAs in HCT116 parental p53 expressing cells over a $48 \mathrm{hr}$ incubation period with $10 \mu \mathrm{M}$ nutlin-3A (A) Fold change of p53responsive miRNAs; miR-34a, miR-143 and, miR-145 in HCT116 parental p53 expressing cells over a $48 \mathrm{hr}$ incubation period with $10 \mu \mathrm{M}$ nutlin-3A (B). Values represent averages from 5 independent experiments expression ratio to GAPDH for mRNAs and miR-103 for miRNAs and normalized to $0 \mathrm{hr}$, *p-value $<0.05$ one-way ANOVA with Tukey post-test using Prism Graphpad. Error bars represent $+/$ - SEM.

\subsection{Disruption of miRNA processing affects the p53 response}

We decided to compare the p53 response in the presence and absence of miRNAs. In miRNA biogenesis there are two key steps that involve micro-processing proteins, these proteins are Drosha and Dicer (Figure 4). The Drosha protein cleaves pri-miRNA into pre-miRNA in the nucleus and Dicer cleaves pre-miRNA into the mature miRNA duplex in the cytoplasm. Both steps have alternative routes as miRNAs from introns can bypass Drosha through the spliceosome and Dicer can be bypassed through slicing activity of the Argonuate protein. However, by knocking out either of these proteins the biogenesis of miRNAs is significantly reduced (Kim et al., 2016). To test the effects of miRNAs on the p53 response we used parental cells along with CRISPR Cas9 knockouts of the Drosha and Dicer genes followed by qRT-PCR using Taqman probes.

Both of the knockout cell lines greatly inhibited miRNA biogenesis as baseline expression levels of target miRNAs; miR-34a, miR-143 and, miR-145 along with the control miRNA 103 
were significantly reduced (Figure 12A). miRNA processing was inhibited more in the Drosha null compared to Dicer null cell lines. Parental cells expressed dramatically elevated target miRNA levels compared to both knockout cell lines, except for miR-143 as it was significantly lower in expression levels compared to the other targets. This expression difference is interesting as miR-143 and miR-145 are produced from the same primary transcript. Following nutlin-3A exposure, all three cell lines behaved similarly as p53 responsive target mRNAs were significantly induced (Figure 12B\&C). The Dicer KO cells did produce a slightly lower initial p53 response compared to either parental or Drosha KO cell lines. Following activation, all three cell lines returned to baseline levels within hours following removal of the drug. This indicates that the initial p53 response and its recovery are not miRNA mediated, and that nutlin-3A treatment is reversible in the presence and absence of miRNAs. 

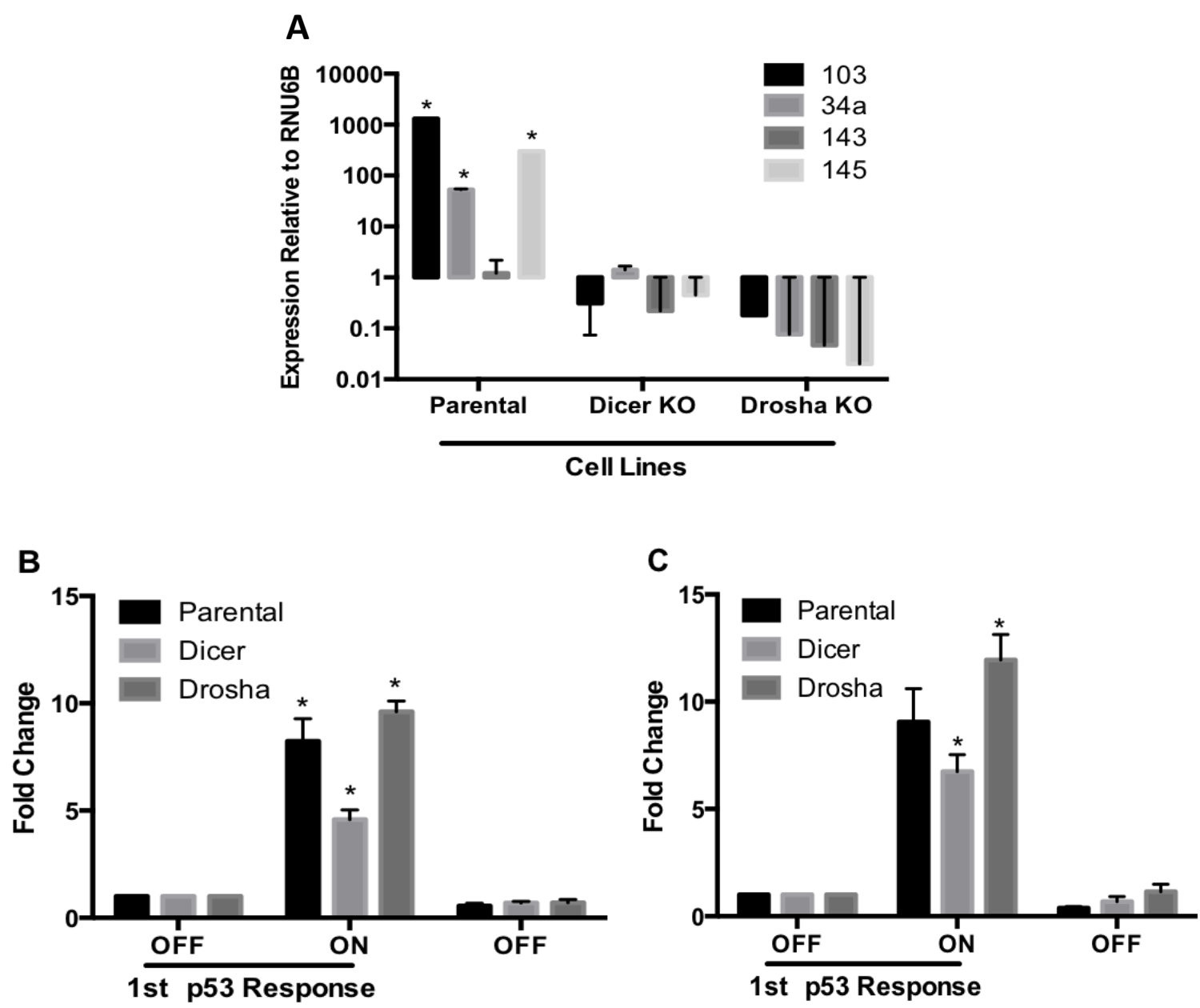

Figure 12. (A) Expression effects of Drosha and Dicer knockout on miRNAs; 103, 34a, 143, and 145. Values are normalized to RNU6B and represent an average of 3 independent experiments. Fold change of MDM2 (B) and CDKN1A (C) in HCT116 parental cells, Dicer and, Drosha KO following $24 \mathrm{hr}$ treatment in $10 \mu \mathrm{M}$ nutlin-3A and $6 \mathrm{hr}$ recovery period. Values represent an average of three experiments and are normalized to GAPDH and $0 \mathrm{hr}$. *p-value $<0.01$ one-way ANOVA with Tukey post-test using Prism Graphpad. Error bars represent +/- SEM. 
3.3 Consecutive 53 responses separated by a period of recovery differ in the presence of miRNAs

Previous work in our lab had indicated that consecutive p53 responses separated by a period of recovery differ (Cabrita et al., 2017). This appeared to be due to miRNA mediated inhibition of a subset of p53-regulated mRNAs (Cabrita et al., 2017). Here, nutlin-3A led to a comparable initial p53 response in all three cell lines. Removal of the drug led to recovery of p53, MDM2 and CDKN1A to basal levels within hours of drug removal and their expression remained at baseline levels without a subsequent challenge (Figure 12 control bar). Adding nutlin-3A again led to an increase in MDM2 and CDKN1A, however, the genotype of the cell lines affected this second response. MDM2 and CDKN1A levels were significantly reduced in the second response compared to initial levels in parental cells (Figure 13A\&B; Table 2). In contrast, MDM2 and CDKN1A were equally induced in Dicer and Drosha knockouts upon re-exposure (Figure 13 C\&D; E\&F; Table 2). These differences suggest that miRNAs play a role in negatively regulating the second p53 response, supporting our previous work (Cabrita et al., 2017). 

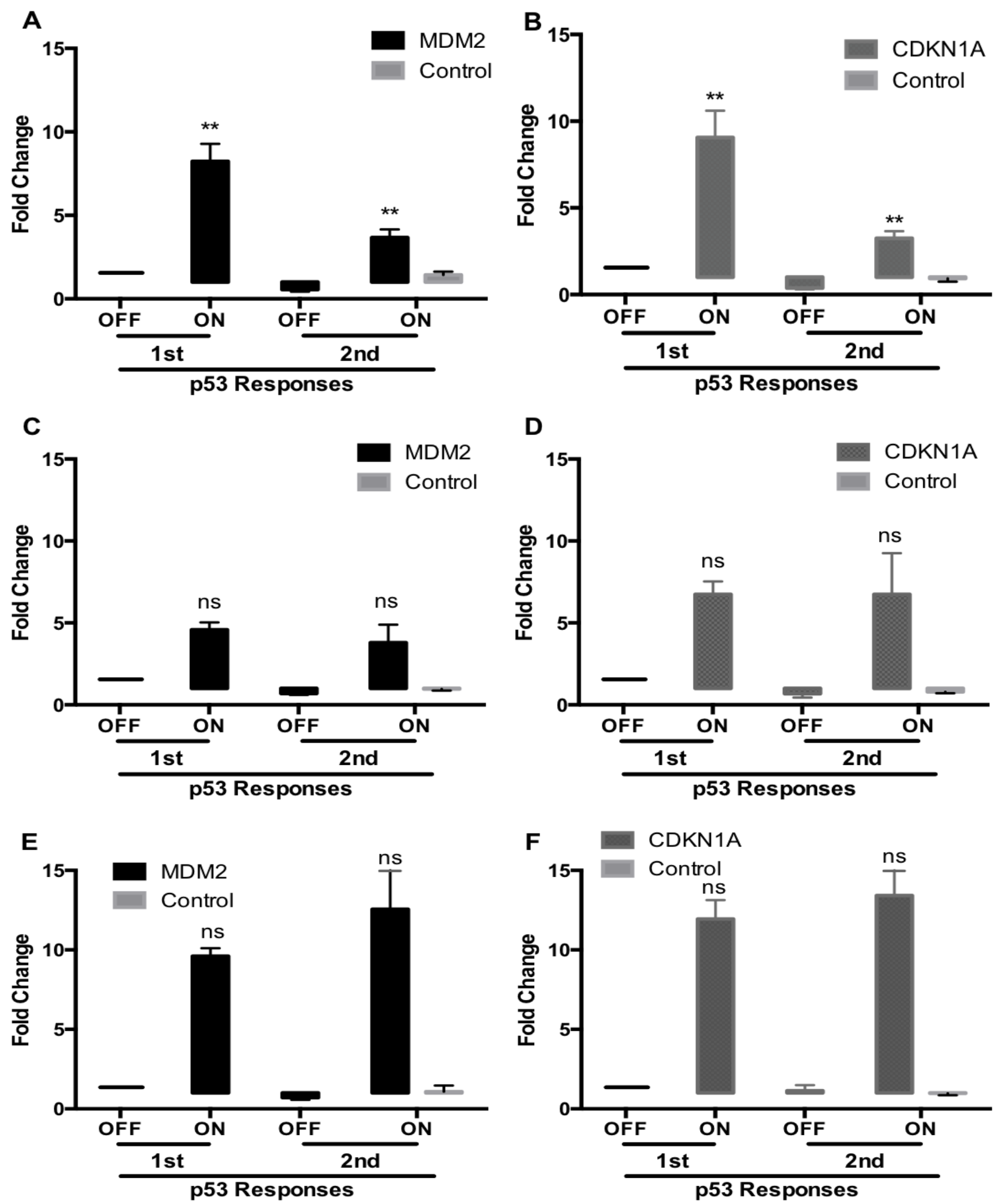

Figure 13. Relative fold change of MDM2 and CDKN1A mRNAs in HCT116 parental cells $(A \& B)$ Dicer knockouts $(C \& D)$ and, Drosha knockouts $(E \& F)$ treated with $10 \mu \mathrm{M}$ nutlin-3A for two consecutive $24 \mathrm{hr}$ periods spaced by a $6 \mathrm{hr}$ recovery period, ND control was treated for one $24 \mathrm{hr}$ period followed by $30 \mathrm{hr}$ recovery. Values represent averages from three independent experiments, normalized to GAPDH and $0 \mathrm{hr} .{ }^{* *} \mathrm{p}<0.01 \mathrm{~ns}=\mathrm{p}>0.05$ one-way ANOVA with Tukey post-test using Prism Graphpad. Error bars represent +/- SEM. 
Table 2. Fold change of p53-responsive MDM2, and CDKN1A mRNAs in HCT116 parental cells, Drosha, and Dicer knockouts (values from Figure 13). Values are normalized to GAPDH, averaged from three independent experiments and shown with standard error and associated pvalues from one-way ANOVA with Tukey post-test using Prism Graphpad. ** $\mathrm{p}<0.01$ one-way ANOVA with Tukey post-test between cell lines using Prism Graphpad.

\begin{tabular}{|c|c|c|c|c|c|c|}
\hline \multirow{2}{*}{\multicolumn{2}{|c|}{ Sample }} & \multicolumn{2}{|c|}{ First p53 Response } & \multicolumn{2}{|c|}{ Second p53 Response } & \multirow{2}{*}{$\begin{array}{c}\text { p-values } \\
1^{\text {st }}-2^{\text {nd }} \text { Response }\end{array}$} \\
\hline & & Fold Change & SEM & Fold Change & SEM & \\
\hline \multirow[t]{2}{*}{ Parental } & MDM2 & $\begin{array}{c}8.23 \\
* *\end{array}$ & 1.04 & 3.24 & 0.40 & $P<0.01$ \\
\hline & CDKN1A & 9.06 & 1.54 & 3.67 & 0.48 & $P<0.01$ \\
\hline \multirow[t]{2}{*}{ Dicer KO } & MDM2 & $\begin{array}{c}4.58 \\
* *\end{array}$ & 0.44 & $\begin{array}{c}3.78 \\
* *\end{array}$ & 1.10 & ns \\
\hline & CDKN1A & $\begin{array}{c}6.47 \\
*\end{array}$ & 0.78 & $\begin{array}{c}6.73 \\
* *\end{array}$ & 2.51 & ns \\
\hline \multirow[t]{2}{*}{ Drosha KO } & MDM2 & $\begin{array}{c}9.60 \\
* *\end{array}$ & 0.49 & $\begin{array}{c}12.55 \\
* *\end{array}$ & 3.27 & ns \\
\hline & CDKN1A & $\begin{array}{c}11.94 \\
*\end{array}$ & 1.18 & $\begin{array}{c}13.42 \\
* *\end{array}$ & 6.99 & ns \\
\hline
\end{tabular}

Immunoblotting was used to determine if RNA levels reflected protein expression within the $\mathrm{p} 53$ response. MDM2 and CDKN1A protein levels were measured by immunoblot in all three cell lines. In parental cells MDM2 exhibited the attenuated second response at the protein level, however, CDKN1A (p21) was not attenuated at the protein level (Figure 14). The attenuated second response appears to affect the protein level for MDM2 but not CDKN1A in parental cells. In comparison the Drosha KO and Dicer KO produced protein levels in the second response that were equivalent to the initial response (Figure 14). The lack of attenuation in the second response was, therefore, consistent between RNA and protein levels in both knockout cell lines. 


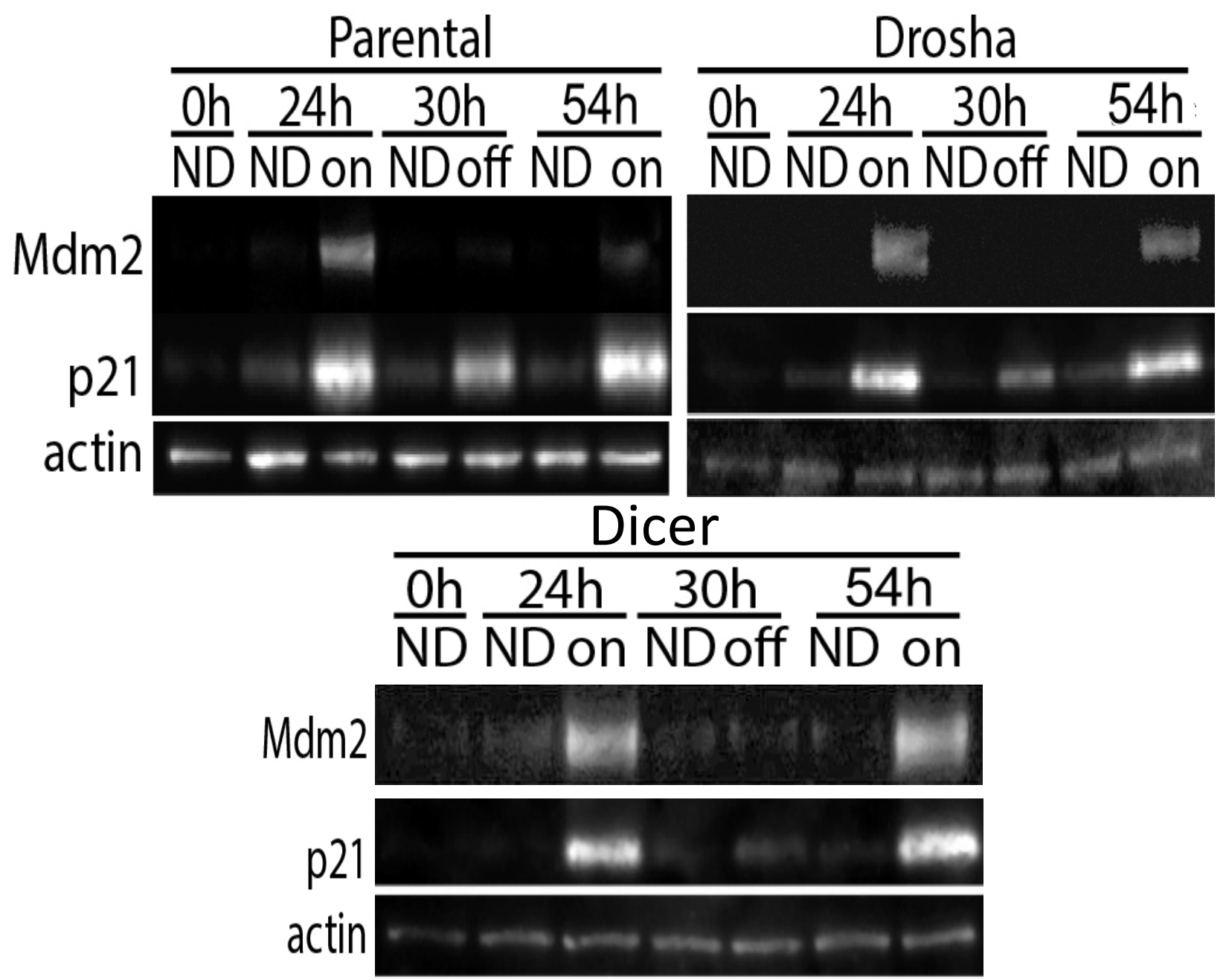

Figure 14. Immunoblot analysis of MDM2 and CDKN1A (p21) protein expression with Actin loading control in HCT116 parental, Dicer KO and, Drosha KO cell lines. Cells were treated with $10 \mu \mathrm{M}$ Nultin-3A $24 \mathrm{hr}$ followed by a $6 \mathrm{hr}$ wash period and a second $24 \mathrm{hr}$ treatment. Membranes were imaged using a Fusion Fx imager and images were quantified using VisionCapt software.

Focusing on miRNAs 34a, 143 and 145, expression was determined under the same conditions as the mRNA. There were no significant changes in expression levels for any of the three miRNAs (Figure 15). Responses produced no significant increase in miRNAs during either the initial or second response (Table 2). Unlike mRNAs, the modest increases in miR-34a and miR-143 were not reversible. Lack of an miRNA response did not fully support the simple model linking increased miRNA expression to the inhibition of MDM2 expression. 


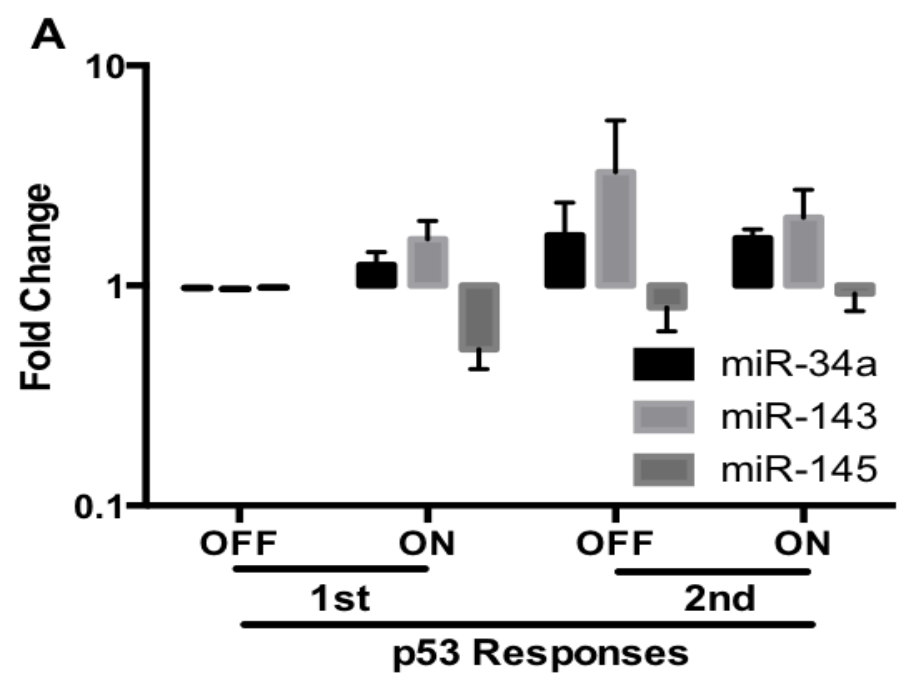

Figure 15. Relative expression of miRNAs 34a, 143, and 145 in HCT116 parental cells (A) Cells were treated with $10 \mu \mathrm{M}$ nutlin-3A for two consecutive $24 \mathrm{hr}$ periods spaced by a $6 \mathrm{hr}$ wash period. Values were normalized to miRNA 103 and $0 \mathrm{hr}$, averaged from three independent experiments with error bars +/- SEM. ns p-values $>0.05$ one-way ANOVA with Tukey post-test using Prism Graphpad.

Table 3. Fold change of miRNAs 34a, 143, and 145 in HCT116 parental cells (from Figure 15). Values are normalized to miRNA 103, averaged from three independent experiments and shown with accompanied standard error values with associated p-values from one-way ANOVA with Tukey post-test using Prism Graphpad.

\begin{tabular}{|c|c|c|c|c|c|}
\hline \multirow{2}{*}{ Sample } & \multicolumn{2}{|c|}{ First p53 Response } & \multicolumn{2}{c|}{ Second p53 Response } & \multirow{2}{*}{ p-values } \\
\cline { 2 - 5 } & Fold Change & SEM & Fold Change & SEM & \\
\hline miR-34a & 1.24 & $\mathbf{0 . 1 8}$ & 1.64 & $\mathbf{0 . 1 5}$ & \\
\cline { 1 - 5 } miR-143 & 1.62 & $\mathbf{0 . 3 4}$ & 2.03 & $\mathbf{0 . 6 9}$ & $\begin{array}{c}\text { p }>0.05 \\
\text { ns }\end{array}$ \\
\hline miR-145 & 0.51 & $\mathbf{0 . 0 9}$ & 0.92 & $\mathbf{0 . 1 5}$ & \\
\hline
\end{tabular}




\subsection{MDM2 3'UTR changes dynamically during $p 53$ activation in the presence/absence of miRNAs}

The 3'UTR of MDM2 is exceptionally long, containing many putative regulatory elements, including miRNA recognition sequences (Melanson et al., 2011; Hoffman et al, 2014). The 3'UTR of MDM2 also contains several putative poly-adenylation sites (Alternative Poly-A Site Database (http://genome.bucm.edu.cn/utr/)). Alternative polyadenylation can include or exclude miRNA recognition sites and alter their context within the UTR. Therefore we performed qRT-PCR analysis using a variety of primer sets that spanned the 3'UTR and SYBR green DNA stain (Figure 16).

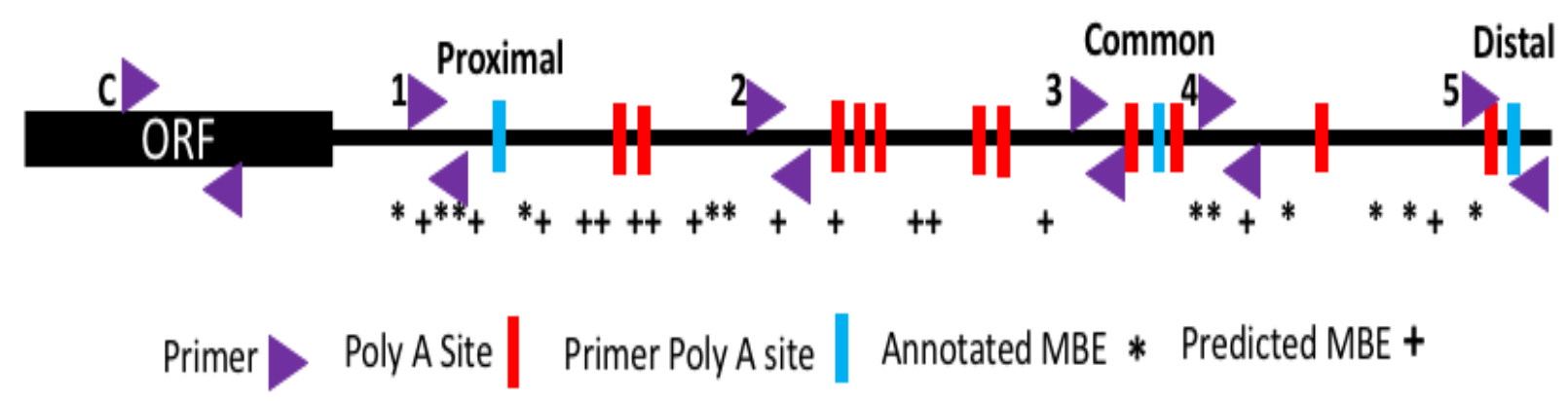

Figure 16. MDM2 transcript and 3'UTR labeled with primers used for UTR analysis, known polyadenylation sites, poly A sites analyzed with primers for 3'RACE, annotated miRNA binding sites (MBEs) and predicted miRNA binding sites for direct MDM2 targeting miRNAs; miR-143, miR145, mIR-192, miR-605, miR-25, miR-32, miR-18b, miR-17, miR-221 and, miR-661.

qRT-PCR was initially performed using five sets of primers using cDNA generated with random hexamers. In HCT116 parental cells primers within the coding region confirmed the initial results using separate primers and Taqman probes (compare Figures 13A and 17A). Specifically, nutlin-3A increased MDM2 levels 10-fold followed by a rapid recovery and an attenuated second p53 response of approximately 4-fold (Figure 17A). There were significant differences depending on the positions amplified within the UTR. The first 3 primer sets along the UTR were induced by nutlin-3A to comparable levels, slightly lower than the coding region. All three primer sets (1-3) were reversibly activated as they rapidly decreased to baseline during the recovery period. 
Following second induction all three primer sets were slightly attenuated, exhibiting the same pattern as the coding region (Figure 17A). The most distal primer set (4) was different from all other 3' UTR regions. Initially the distal region was less well represented in the transcript but it increased more in response to nutlin-3A treatment, suggesting that a longer transcript was better represented within the cDNA samples. This long transcript was still reversible and induced equally well when cells were re-exposed to nutlin-3A again. These results indicate that in the parental cells it is transcripts that terminate between primers sets 3 and 4 that fail to be induced during the second nutlin-3A treatment, while the less abundant longer variant is induced equally well in response to both nutlin-3A exposures.

Knockout cells displayed a much different profile along the 3'UTR compared to the parental cells. In Dicer KO cells, MDM2 was induced by nutlin-3A, recovered to baseline levels rapidly when the drug was removed and was induced equally well when re-exposed to this drug. All primer sets in the 3'UTR detected similar changes in MDM2 expression (Figure 17B).

Drosha KO cells were somewhat different. The initial coding response was comparable to the parental cells, recovered to baseline levels following removal of the drug but MDM2 increased far higher when exposed to nutlin-3A a second time. Primers amplifying near the proximal region of the 3'UTR detected similar changes in MDM2 expression. There was a large fold increase in the presence of nutlin-3A, followed by recovery to baseline levels and then an even larger increase when cells were exposed to nutlin-3A again (Figure 17C). The distal primers did not detect this exaggerated second response. Therefore, there was a dramatic difference in the patterns of nutlin3A induced MDM2 expression between parental and the Drosha null cell line. This indicates that there are dynamic changes in MDM2 3'UTR profiles in the presence and absence of miRNAs that largely affect more proximal UTR regions. 


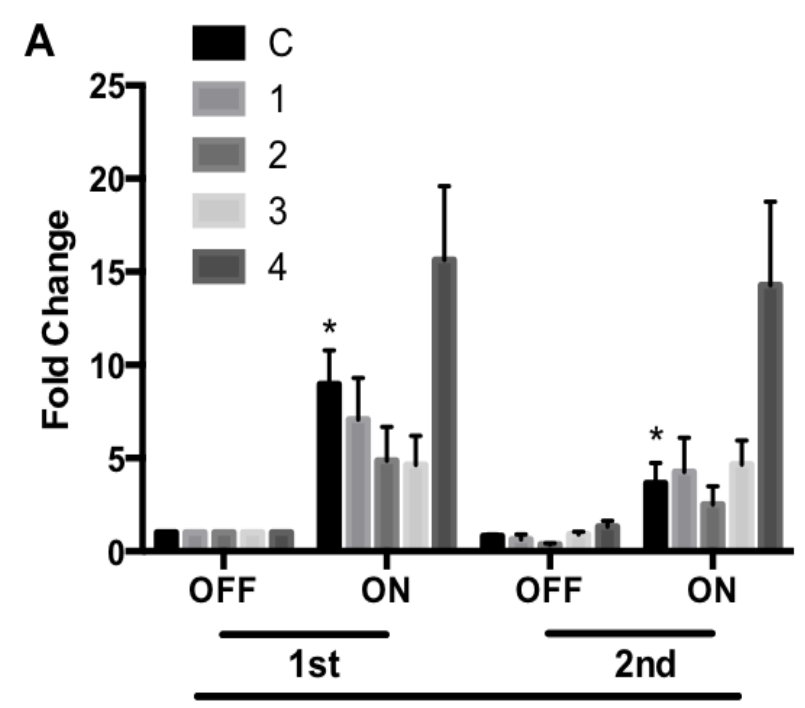

p53 Responses

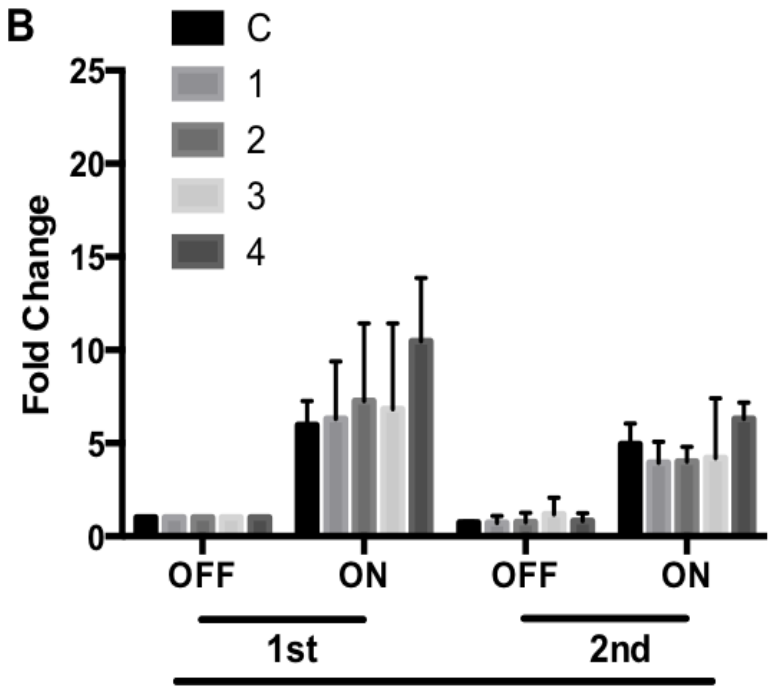

p53 Responses

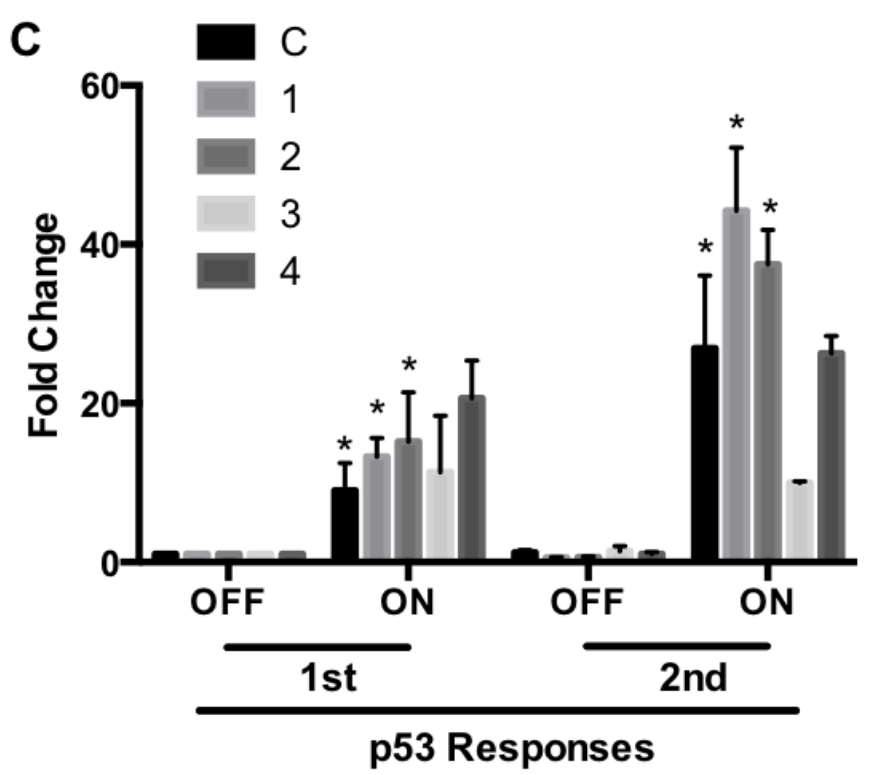

Figure 17. Fold change of the MDM2 coding region and 3'UTR regions for HCT116 parental (A), Dicer (B) and Drosha KO (C) cell lines. Cells were treated with $10 \mu \mathrm{M}$ nutlin-3A for one $24 \mathrm{hr}$ period followed by a $6 \mathrm{hr}$ wash period and a second $24 \mathrm{hr}$ treatment. Each bar represents an average +/- SEM of three independent experiments, values are normalized to GAPDH with fold change relative to $0 \mathrm{hr}$. * indicates significance with a p-value $<0.01$ from one-way ANOVA with Tukey post-test using Prism Graphpad. RNA was collected and reverse transcribed using random hexamer primers. 
The differences in response detected at the 3' end motivated us to consider differences in polyadenylation site usage among cell lines. cDNA generated using random primers represent sequence fairly independent of position in the mRNA. Conversely, oligo-dT primed cDNA synthesis extends from poly A sites and thus over-represent 3'ends. This bias was used to determine if any of these primer sets were under- or over-represented due to distance from 3'UTRs. In HCT116 parental cells, there was heterogeneity in the initial MDM2 response detected at each position during the p53 response. The region amplified by primer 2 was under-represented (not well induced) while the region amplified by primer 4 was over-represented (Figure 18A). The signal detected by primer set 1 increased to a similar level to the coding region and recovered to baseline levels after drug removal. Meanwhile, primer sets 3 and 4 detected increased MDM2 expression initially but these remained slightly elevated following recovery (Figure 18A). When exposed to nutlin-3A a second time, the primer sets 3 and 4 increased equally well while the more proximal primer sets failed to detect a full second response (Figure 18A). These results suggest that at least two populations of transcripts contribute to the qRT-PCR signal. One is polyadenylated between primer sets 3 and 4 and the second is polyadenylated to the 3 ' side of primer set 4 .

Important differences were observed in the Drosha KO cells, when analyzing oligo-dT cDNA by qRT-PCR. First, there was less heterogeneity in the MDM2 response detected with each primer set and each primer set detected recovery to baseline levels following removal of the drug (Figure 18B). Second, the fold increase in expression observed in Drosha null cells upon nutlin3A treatment was about 2 fold higher than that observed in parental controls (Figure 18B). Third, the pattern of MDM2 induction detected when cells were re-exposed to nutlin-3A was highly dissimilar in Drosha null cells compared to the parental cell line. The coding, region 1 and region 2 primers detected an increase in MDM2 that exceeded the initial response while these primer sets 
detected a reduced secondary response in parental cells. Lastly, the more distal primer sets detected roughly equivalent responses to nutlin-3A treatments (Figure 18B). Taken together, these results suggest that the presence or absence of miRNAs only affects expression levels of mRNAs that terminate in a central region of the 3'UTR whereas transcripts containing the longest 3'UTRs do not appear to be affected by miRNAs.

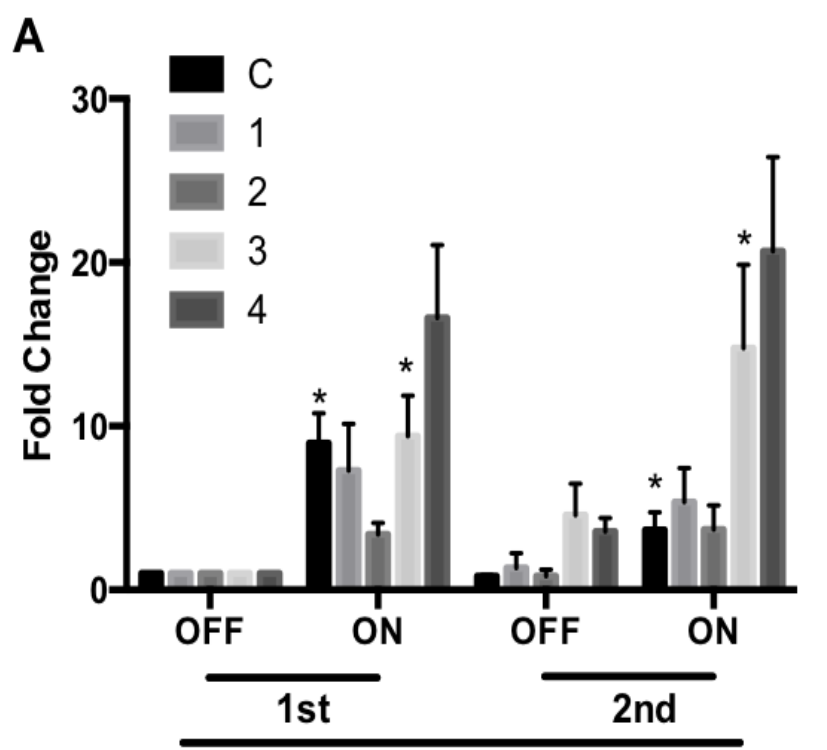

p53 Responses
B

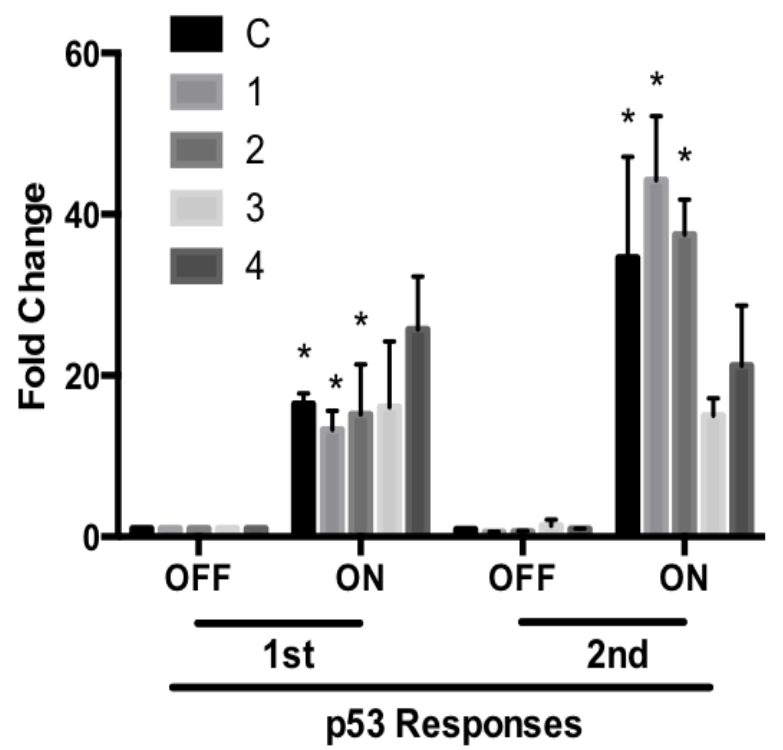

Figure 18. Fold change of the MDM2 coding region and 3'UTR regions for HCT116 parental (A) and, Drosha KO (B) cell lines. Cells were treated with $10 \mu \mathrm{M}$ nutlin-3A for one $24 \mathrm{hr}$ period followed by a $6 \mathrm{hr}$ wash period and a second $24 \mathrm{hr}$ treatment. Each bar represents an average $+/-$ SEM of three independent experiments, values are normalized to GAPDH with fold change relative to $0 \mathrm{hr} . *$ indicates significance with a p-value $<0.01$ from one-way ANOVA with Tukey post-test using Prism Graphpad. RNA was collected and reverse transcribed using oligo-dt16 primers.

There is evidence from high throughput sequencing strategies that the 3' UTR of MDM2 can be polyadenylated at multiple sites (http://genome.bucm.edu.cn/utr/)(Figure 16). We used 3' rapid amplification of cDNA ends (3'RACE) to identify poly-A sites used in all 3 cell lines. We designed primers paired with an anchored oligo-dT primer with a linker that served as a reverse primer that could be used in combination with forward primers in different regions of the 3'UTR. 
This allowed us to PCR amplify 3'ends for agarose gel electrophoresis and DNA sequencing at Stemcore Laboratories, Ottawa Hospital Research Institute.

We detected polyadenylated forms of MDM2 in 3 of the 4 regions tested. We did not detect polyadenylation within intron 4 of MDM2, a variant form of MDM2 that has been detected through next generation sequencing (http://genome.bucm.edu.cn/utr/). The precise position of the 3 poly-A sites were confirmed by direct sequencing of PCR products and bands excised from agarose gels. The poly-A sites detected were consistent with forms annotated in the 3'UTR database (http://genome.bucm.edu.cn/utr/)(Figure 19). Interestingly, only 2 of the 3 polyadenylated forms were detected in the parental strains while all 3 were detected in the knockout cell lines (Figure 19). This suggests that the most proximal poly A site was not used in the parental cell line but it was used in the Drosha and Dicer KO cell lines (Figure 19). Therefore, the Drosha and Dicer genotypes of the cell lines affected our ability to detect specific polyadenylated forms of MDM2 mRNA.

\section{Proximal Poly A Sequence}

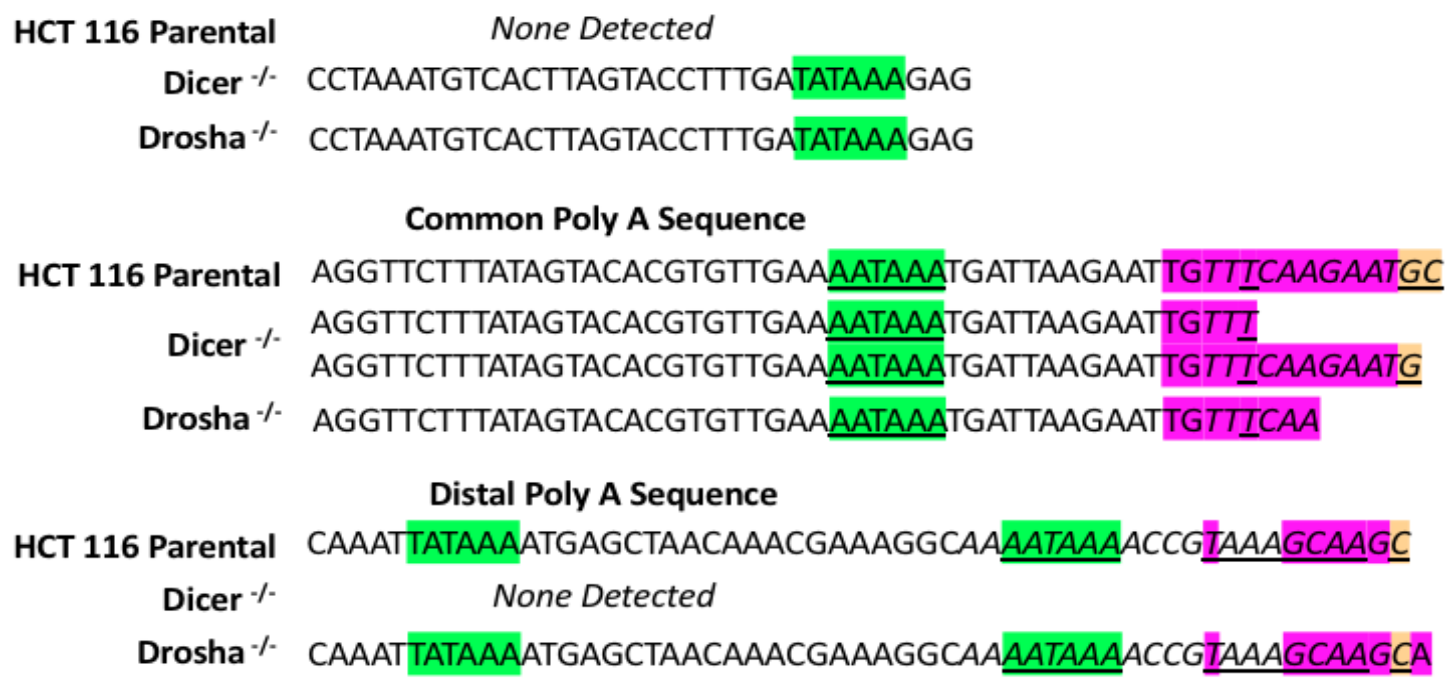

Figure 19. 3'RACE MDM2 cDNA poly A region sequencing results for HCT116 parental, Dicer and Drosha KO cell lines. Poly A signal sequences are highlighted in green with poly A sites highlighted in purple. qPCR products were separated on a $\%$ agarose gel, bands were excised, purified and sent for sequencing at Stemcore Laboratories, OHRI. Samples for each poly A site were sequenced and results were blasted to identify sequence match with MDM2. 


\section{Discussion}

The p53 protein is a critical component in the protection of cells from tumorigenesis, therefore, understanding how it responds is extremely important to survival of cells. We had previously reported that two p53 responses separated by a period of recovery could be induced in cells expressing a temperature sensitive variant of $\mathrm{p} 53$. Under these conditions, specific mRNAs, including MDM2, were not induced as strongly in response to the second challenge (Cabrita et al., 2017). From this work, our lab proposed a potential link between p53-induced miRNAs and the inhibition of subsequent p53 transcriptional responses. This is potentially significant as standard cancer therapies are fractionated. Our data suggested that specific p53-regulated miRNAs formed a post-transcriptional feedback loop, preventing repetitive p53 responses (Cabrita et al., 2017). In this study, we used one of the most effective and reversible inhibitors of MDM2 (nutlin-3A) to activate the 553 response. Nutlins are molecules that bind to the pocket on MDM2 that associates with p53, therefore, competitively inhibiting its regulatory control (Heintz et al., 2017). These molecules are known to only affect MDM2 interaction with p53 and have no other known offtarget effects within the $\mathrm{p} 53$ response. This provided a sound model for activating the p53 response reversibly.

\section{1 p53 responses separated by a period of recovery appear to be attenuated in the presence of miRNAs}

The effect of nutlin-3A on the expression of known p53-responsive mRNAs was assessed in HCT116 cells expressing wildtype p53. The pattern detected supported our previous work with HT29 cells expressing a temperature sensitive variant of p53 (Cabrita et al, 2017). Nutlin-3A exposure both activated a p53 transcriptional response, and was reversible, as p53-responsive mRNAs like MDM2 and CDKN1A rapidly returned to baseline upon drug removal (Figure 13A\&B). When challenged with a second identical exposure to nutlin-3A, the induction of MDM2 
and CDKN1A was attenuated compared to the first treatment. The corresponding MDM2 protein was similarly attenuated, but the p21 protein encoded by CDKN1A was not. It is not uncommon for protein levels to differ from RNA levels (Maier et al., 2009). Within a total mRNA population for a gene, there are a number of mRNAs transcribed, not all of which code for protein. It is possible that attenuation of CDKN1A predominantly affects non-coding transcripts or a population of RNAs that are not translated for other reasons, leading to the discrepancy between RNA and protein levels. Nonetheless, our results supported our previous work at the RNA level.

The effect of nutlin-3A on the expression of known p53-responsive miRNAs was similarly assessed in HCT116 cells, as we had previously suggested that the attenuation of these mRNAs was miRNA mediated (Cabrita et al., 2016; Cabrita et al., 2017). From this work there were a subset of miRNAs that were highly expressed during p53 activation including; miR-34a, miR143 and miR-145 (Cabrita et al., 2016). Given their previous p53-responsive expression and targeting of our measured mRNA we analyzed their expression in our current model. First, cells were continuously exposed to $10 \mu \mathrm{M}$ of nutlin-3A for $48 \mathrm{hrs}$. Under these conditions, miR-34a, miR143 and miR-145 appeared to increase within 8 hours and remain elevated, like p53-induced mRNAs, but these changes in miRNA levels were not statistically significant (Figure 11A\&B). Therefore, these p53-inducible miRNAs were not induced as strongly as MDM2 or CDKN1A. Second, miRNA levels were assessed in response to two nutlin-3A treatments separated by a period of recovery. Here, there were also no consistent changes in miRNA levels that could readily account for the observed effects on MDM2 and CDKN1A mRNA expression. Taken together, these results suggest that $\mathrm{p} 53$ responses activated consecutively separated by a period of recovery are not equivalent, but the role miRNAs might play was unclear. 


\section{2 p53 responses separated by a period of recovery in miRNA deficient cells are not attenuated}

Isogenic HCT116 cells in which either Drosha or Dicer were knocked out with CRISPRCas9 were analyzed in the same way. The response to nutlin-3A exposure was normal in both cell lines, with MDM2 and CDKN1A levels returning to baseline rapidly following drug removal. Therefore, the nutlin-3A treatment is reversible and recovery is not miRNA mediated. Unlike the parental HCT116 cell line, MDM2 and CDKN1A were induced to the same or higher levels when exposed to a second nutlin-3A treatment.

Given the second p53 response was as large or larger than the first in the miRNA processing defective cell lines, this suggests that one or more miRNAs negatively regulate the p53 response. However, none of the three tested p53-responsive miRNAs; miR-34a, miR-143 and, miR-145 responded to treatment (Figure 14). This was clearly different from the previous work in our lab (Cabrita et al., 2016), yet evidence in the Drosha and Dicer nulls still supports the overall hypothesis. With no changes in measured miRNA levels the question of how the second response could be attenuated shifted our attention to potential interactions. As the population of miRNAs analyzed is small in comparison, and many other miRNAs bind to the mRNA targets, it is possible that other miRNAs change in expression. However, both miR-143 and miR-145 are major regulators of MDM2 (Zhang et al., 2013) and baseline levels of miRNAs were 100-fold higher in the HCT116 cells compared to the previous temperature sensitive HT29-tsp53 cells. It was, therefore, more likely that the MDM2 and CDKN1A mRNAs escaped miR-34a-, miR-143- and miR-145-mediated repression.

\subsection{Dynamic changes occur within the 3'UTR of MDM2 following p53 activation}

There is a large body of research linking p53 to downstream miRNA targets, and within this network there are a number of feedback and feedforward systems that involve miRNAs (Feng 
et al., 2011, Hermeking, 2012; He et al., 2007; Raver-Shapira et al., 2007). Targets of p53 are also affected by chemotherapeutic treatments, as miR34a is phosphorylated in its 5' region by ATM during radiation exposure, leading to increased loading into the RISC complex with AGO2 (Salzman et al., 2015). This effect does not change the expression of 34a but rather its activity levels. There are many other interactions that could play into this system, including the site of miRNA-mRNA binding which is the 3'UTR.

The 3'UTR of MDM2 is about $7 \mathrm{~kb}$ in length, containing many putative regulatory elements, including miRNA recognition sequences (Melanson et al., 2011; Hoffman et al, 2014). The 3'UTR of MDM2 also contains several putative poly-adenylation sites (Alternative Poly-A Site Database (http://genome.bucm.edu.cn/utr/)). We hypothesized that differences in poly-A site usage could affect susceptibility to miRNA-mediated repression. We used qRT-PCR with several sets of primers, spanning from the coding region through to the distal end of the 3'UTR to determine if there were alterations in 3 ' ends during the p53 response.

We used both cDNA generated with random hexamers and oligo-dT primers. Random primers will bind along the entire transcript to initiate reverse transcription evenly across the RNA sequence. Oligo-dT can give a different picture as these primers bind long runs of adenosines, mainly binding poly A tails and preferably representing mRNAs at their 3 'ends. These approaches yielded complementary information that allowed us to determine that distinct populations of MDM2 mRNAs, with distinct polyadenylation sites were produced, and that specific polyadenylated forms were subject to miRNA-mediated inhibition of MDM2 expression. Specifically, transcripts that terminated between primers 3 and 4 ('common' in Figure 16) appeared to be uniquely inhibited in HCT116 cells, but not the isogenic miRNA processing defective lines. There was no apparent inhibitory effect on transcripts with the longer 3'UTR 
polyadenylated at the distal site (Figure 16). Therefore, distinct alternatively polyadenylated forms of MDM2 were differentially susceptible to miRNA-mediated regulation.

Regulation of poly-adenylation is controlled by upstream signal sequences that facilitate poly adenylation machinery and recognition of the cleavage site (Derti et al, 2012). Poly adenylation does not utilize one specific site in the 3'UTR, as 70\% of known human genes contain more than 1 (Derti et al., 2012; Tian et al., 2005). The use of multiple poly adenylation sites (APA) has not been fully elucidated, although, upregulation/downregulation of various factors and tissue specific characteristics along with the poly A machinery lead to the use of different cleavage sites (Akman et al., 2015; Elkon et al., 2012; Gruber et al., 2012; Martin et al., 2012; Masamha et al., 2014). There are many implications of APA, as the alternative cleavage of the 3'UTR can dramatically change its characteristics. Along the 3'UTR there are many regulatory elements that include; trans-elements like RBPs and miRNAs and, cis elements such as AREs and GREs (Matoulkova et al., 2012; Halees et al., 2011). As these sites are spread out across the 3'UTR, APA resulting in longer or shorter transcripts changes the number of these sites present and their context within the 3' UTR. MDM2 itself has an abnormally long 3'UTR that contains many polyadenylation sites and a large number of regulatory elements, more specifically miRNA binding sites, throughout its UTR (Figure 16). This allows for APA to dramatically change the characteristics included in the 3'UTR of MDM2.

Using the 3'RACE assay and direct sequencing of 3'RACE products at key regions in the UTR, we were able to determine relative usage of sites. Sequencing of 3'RACE samples (Figure 19) showed that HCT116 cells use the common and distal sites, while Drosha and Dicer knockout cell lines use a mix of the proximal, common and distal sites (see Figure 16 for locations). Together the data shows that parental cells predominantly produce longer transcripts, and the intermediate 
transcripts (terminating at the common poly A site in figure 16) appear to be inhibited by miRNAs. In the absence of miRNAs in Drosha KO cells, these intermediate transcripts are overexpressed in the second response. It may seem counter-intuitive that transcripts terminating earlier are more susceptible to miRNAs, as these 3'UTRs share the same proximal miRNAs sites and the shorter transcript contains fewer miRNA sites overall. Clearly the number of sites alone and even the sequence of specific sites is insufficient to explain this pattern.

The shortening and lengthening of 3'UTRs has been documented in various tissues. Shorter 3'UTRs may result in the elimination of miRNA recognition sites, and thus evasion of miRNA inhibition and depression of gene expression (Xiang et al., 2018). When an APA site is used the entire downstream region of the pre-mRNA to that site is removed, along with all of its potential regulatory elements. However, this shortening can also bring specific elements upstream of the poly A site closer to the end of the transcript, changing the presentation of these sites. Although removal of miRNA binding sites can aid in evasion of inhibitory control, it can also potentiate other dormant miRNA binding sites that were previously masked by the RNA structure, making inaccessible sites accessible. In fact, this has been documented in a cell specific manner as miRNA sites closer to the 3' end showed increased repressive function (Nam et al., 2014). Shortening of the 3'UTR to precisely downstream of a miRNA binding site appears to occur in genes induced during differentiation that are targets of miRNAs also induced during proliferation and cancer (Hoffman et al., 2016). There are genes with conserved miRNA binding sites (MBEs), enriched 5' to multiple APA sites throughout the 3'UTR (Hoffman et al., 2016). Placement of sites in this manner allows for the coordination of APA and miRNA-mediated regulation of gene expression.

Again, the picture becomes increasingly complex as proto-oncogenes can escape miRNA regulation by using APA to remove miRNA binding sites, and anti-proliferative genes can use 
APA to induce miRNA regulation by cleaving adjacent to MBEs, increasing their functionality (Hoffman et al., 2016). This could lead to attenuation of shorter transcripts and a shift to longer transcripts for MDM2, as miRNA binding sites may have higher affinity for binding in the proximal region, suppressing these transcripts. In the absence of miRNAs, shorter transcripts could then be produced uninhibited and therefore favor this population over longer 3'UTRs. The MDM2 3'UTR contains a large number of alternative polyadenylations sites and many miRNA binding sites (Figure 16). There are clusters of miRNA binding sites around poly A sites (see common site in Figure 16), it could be that transcripts terminating in this region allow for easier access to these MBEs compared to sites close to more distal poly A sites due to RNA folding. The secondary structure of the RNA could vary between transcripts, especially those with full length UTRs, and may contribute to the accessibility of MBEs. It was recently reported (Thivierge et al., 2018) that a similar mechanism occurs in the PTEN gene, a protein that is also involved in the p53 network, playing a role in apoptosis (Stambolic et al., 2001). Using 3'RACE and reporter constructs, Thivierge et al., 2018, analyzed the expression of various regions throughout the 3'UTR of the PTEN mRNA. In this study they discovered a similar pattern, whereby shorter transcripts were heavily regulated by miRNAs in comparison to longer transcripts. The more stable transcripts using distal poly A sites matches the findings of our study. This mechanism of miRNA regulation and APA is clearly present in more than one mRNA, and the present work adds to this new and somewhat counter intuitive form of post-transcriptional regulation of gene expression.

We also made an unexpected and somewhat fortuitous finding in sequencing 3 'RACE products while this thesis was in preparation. The MDM2 3'UTR contains a region in the central 3'UTR with 5 sequence repeats of around 50 nucleotides, all clustered within a few base pairs of each other. To the best of our knowledge, the existence of these repeat sequences have never been 
reported previously. Although it is unknown what the function of these repeated sequences are, they may play some regulatory role affecting shorter length transcripts. These repeats are located immediately upstream of the most commonly used poly A site (Alternative Poly-A Site Database (http://genome.bucm.edu.cn/utr/)). As transcripts terminating downstream of these elements are subject to miRNA-mediated inhibition of gene expression, it is possible that these elements affect miRNA binding. There is research that indicates a link between Alu elements and miRNA binding (Smalheiser \& Torvik, 2005; Piriyapongsa et al., 2007; Yuan et al., 2010; Dahary et al., 2011). These transposable elements may provide miRNA binding sites and occur multiple times within the same UTR, similar to our 50bp repeat discovered in the MDM2 3'UTR. Although most sites are likely non-responsive, there have been links between miRNA function and Alu elements such as with miR-661 (Hoffman et al., 2014). Interestingly miR-661 is known to directly target MDM2, whether this is leftover sequence from a transposable element or some form of regulatory sequence is not yet known and requires more research to determine its effects.

\subsection{Drosha and Dicer knockout effects on cells}

The Dicer KO cells throughout the data reflect an intermediate between the parental and Drosha KO cells. There were no significant increases or decreases for mRNAs in any experiments, and initial responses were significantly lower than both the parental and Drosha KO cells. This suggests that Drosha knockout may have a much larger effect on the cell compared to Dicer knockout. It has recently been discovered that Drosha holds a number of functions beyond miRNA biogenesis (Lee \& Shin, 2017). These roles include minor mRNA cleavage ability, ribosomal biogenesis and transcriptional activation through 5' binding. Globally, knockout of Drosha may affect many more cellular functions than miRNA biogenesis compared to Dicer knockout. 
Implications that are unknown in the context of p53 responses, but may play a role in the differences generated between the Dicer KO and Drosha KO cell lines in our experiments.

\section{5 p53 responses and cancer therapy}

The p53 response is known to be activated by DNA damaging agents and genotoxic stresses, much of which are employed in cancer therapies such as; chemotherapy and radio-therapy fractions daily. With known activation of the p53 response during cancer therapy, there is a need to understand how this protein reacts over treatment protocols in both target cancer cells and normal healthy tissue. Similar to our model, therapy protocols do not consist of one single treatment. In fact, they typically follow multiple treatments for extended periods of time in a fractionated setting. Likewise, in our daily routine our bodies and cells are constantly exposed to DNA damage in waves. The p53 protein is known to be activated within 1 hour of treatment. p53 has also been reported to act in pulses, with frequencies that can alter the expression profiles of its targets (Porter et al., 2016). p53 is not only a target for cancer therapy but also a predictive biomarker, as p53 expression levels and its targets can be used to determine treatment outcome (Chmara et al., 2018, Chen et a., 2012). To do this we need to fully understand how the p53 response acts following activation in multiple scenarios. Our model is especially applicable to treatment procedures, and may provide insight into how the p53 protein behaves and what impacts this may have on the response in cells.

\section{Conclusion}

This project was initiated with the hypothesis that miRNAs modulate the p53 response. Our data supports this hypothesis as we detected measurable differences in the p53 response in isogenic cell lines unable to process miRNAs. When p53 is activated consecutively separated by a period of recovery the responses were not equal in HCT116 parental cells. The second response 
was attenuated when examining MDM2 and CDKN1A mRNAs in the presence of miRNAs. This attenuation was not evident in either of the micro-processing knockouts. This strongly supports the original hypothesis that miRNAs play a role in modulating p53 in a fractionated setting. Although, the mechanism is not as simple as initially anticipated. The pattern of expression could not simply be explained by changes in miRNA levels in response to p53 activation. Instead we detected alterations in the pattern of polyadenylation that likely contributed to differential posttranscriptional regulation.

The significance of these findings points towards a mechanism of miRNA modulation that involves alternative polyadenylation. This miRNA modulation appears to have some connection with transcript length and poly A site usage. The interaction between miRNAs and alternative polyadenylation is a complex regulatory loop that has now been uncovered in two p53 targets, and may occur in other systems. Targeting of specific transcripts provides another degree of complexity to miRNA binding sites, as their context within the UTR clearly affects interactions and shows a new level of regulation within the $\mathrm{p} 53$ response. The exact mechanism between alternative polyadenylation and miRNAs still needs to be studied to determine if miRNAs actively regulate APA, or if these two processes combined lead to the attenuation in the p53 response and shift in profiles. 


\section{References}

Agarwal V., et al. Predicting effective microRNA target sites in mammalian mRNAs. eLife. 2015; 4: e5005.

Akman BH., Can T., \& Erson-Bensan AE. Estrogen-induced upregulation and 30-UTR shortening of CDC6. Nucleic Acids Res. 2012; 40: 10679-88.

Akman HB., et al. 30UTR shortening and EGF signaling: implications for breast cancer. Hum Mol Genet. 2015; 24: 6910-20.

Alexandropoulos K., Cheng G. \& Baltimore D. Proline-rich sequences that bind to Src homology 3 domains with individual specificities. (1995) Proc. Natl. Acad. Sci. USA. 1995 ; 92: 3110-3114.

Alló M., et al. Control of alternative splicing through siRNA-mediated transcriptional gene silencing. Nat. Struct. Mol. Biol. 2009; 16: 717-724.

Ameyar-Zazoua M., et al. Argonaute proteins couple chromatin silencing to alternative splicing. Nat. Struct. Mol. Biol. 2012; 19: 998-1004.

Apella E., \& Anderson CW. Post-translational modifications and activation of p53 by genotoxic stresses. Eur. Jour. Biochem. 2001; 268: 2764-2772.

Attardi LD., et al. PERP, an apoptosis-associated target of p53, is a novel member of the PMP22/gas3 family. Genes and Develop. 2000; 12: 704-718.

Atwood BL., et al. Human Argonaute 2 is tethered to ribosomal RNA through microRNA interactions. J. Biol. Chem. 2016; 291: 17919-28.

Bagga S., et al. Regulation by let-7 and lin-4 miRNAs results in target mRNA degradation. Cell. 2005; 122: 553-563.

Bai B., Liu H., \& Laiho M. Small RNA expression and deep sequencing analyses of the nucleolus reveal the presence of nucleolus-associated microRNAs. FEBS Open Bio. 2014; 4: $441-449$.

Baptiste N., et al. The proline-rich domain of p53 required for cooperation with anti-neoplastic agents to promote apoptosis of tumor cells. Oncogene. 2002; 21: 9-21.

Bartel DP. MicroRNAs: genomics, biogenesis, mechanism, and function. Cell. 2004; 116: 281-297.

Beausejour CM., et al. Reversal of human cellular senescence: roles of the p53 and p16 pathways. EMBO J. 2003; 22:4212-22. 
Bennett M., et al. Cell surface trafficking of Fas: a rapid mechanism of p53-mediated apoptosis. Science. 1998; 282: 290-293.

Bohnsack MT., et al. Exportin 5 is a RanGTP-dependent dsRNA-binding protein that mediates nuclear export of pre-miRNAs. RNA. 2004; 10: 185-191.

Borellini F., \& Glazer RI. Induction of Sp1-p53 DNA-binding heterocomplexes during granulocyte/macrophage colony-stimulating factor-dependent proliferation in human erythroleukemia cell line TF-1. J Biol Chem. 1993; 268: 7923-7928.

Bouillet P., \& Straser A. BH3-only proteins - evolutionarily conserved pro-apoptotic Bcl-2 family members essential for initiating programmed cell death. J. Cell Sci. 2002; 115: 1567-1574.

Boudreau RL., et al. Transcriptome-wide discovery of microRNA binding sites in human brain. Neuron. 2014; 81: 294-305.

Bouvard V., et al. Tissue and cell-specific expression of the p53-target genes: bax, fas, $\mathrm{mdm} 2$ and waf1/p21, before and following ionizing irradiation in mice. Oncogene. 2000; 19: 649-660.

Brady CA., et al. Distinct p53 transcriptional programs dictate acute DNA-damage responses and tumor suppression. Cell 2011; 145: 571-583.

Brennecke J., et al. Principles of microRNA-target recognition. PLoS Biol. 2005; 3: e85.

Bunz F., et al. Requirement for p53 and p21 to sustain G2 arrest after DNA damage. Science 1998; 282:1497-1501.

Burns DM., et al. CPEB and two poly(A) polymerases controlmiR-122 stability and p53 mRNA translation. Nature. 2011; 473: 105-8.

Burns DM., \& Richter J. CPEB regulation of human cellular senescence, energy metabolism, and p53 mRNA translation. Genes Dev. 2008; 22: 3449-60.

Cabrita MA., et al. The p53 protein induces stable miRNA that have the potential to modify subsequent p53 responses. Gene. 2017; 608:86-94.

Cabrita MA., et al. A Temperature Sensitive Variant of p53 Drives p53-Dependent MicroRNA Expression without Evidence of Widespread Post-Transcriptional Gene Silencing. PloS one. 2016; 11(2).

Charlesworth A., et al. Musashi regulates the temporal order of mRNA translation during Xenopus oocyte maturation. EMBO J. 2006; 25: 2792-2801. 
Chendrimada T P., et al. TRBP recruits the Dicer complex to Ago2 for microRNA processing and gene silencing. Nature. 2005; 436: 740-744.

Chen J., et al. Separate domains of p21 involved in the inhibition of Cdk kinase and PCNA. Nature 1995; 374: 386-388.

Colgan DF., \& Manley JL. Mechanism and regulation of mRNA polyadenylation. Genes Dev. 1997; 11: 2755-2766.

Coller J., \& Parker R. Eukaryotic mRNA decapping. Annu. Rev. Biochem. 2004; 73: 861-890.

Coller JM., et al. The DEAD box helicase, Dhh1p, functions in mRNA decapping and interacts with both the decapping and deadenylase complexes. RNA. 2001; 7: 1717-1727.

Dahary D. CpG Islands as a putative source for animal miRNAs: evolutionary and functional implications. Mol. Biol. Evol. 2011; 28: 1545-1551.

Daniel C., et al. A novel miRNA processing pathway independent of Dicer requires Argonuate2 catalytic activity. Science. 2010; 328:1694-1698.

De Moor CH., \& Richter JD. Cytoplasmic polyadenylation elements mediate masking and unmasking of cyclin B1 mRNA. EMBO J. 1999; 18: 2294-2303.

Deng C., et al. Mice Lacking p21 CIP1/WAF1 undergo normal development, but are defective in G1 checkpoint control. Cell. 1995; 82: 675-684.

Deng G., \& Sui G. Noncoding RNA in oncogenesis: A new era of identifying key players. Int J Mol Sci. 2013; 14: 18319-18349.

Derti A., et al. A quantitative atlas of polyadenylation in five mammals. Genome Res. 2012; 22: 1173-83.

Devany EC. Positive and negative feedback loops in the p53 and mRNA 3'processing pathways. PNAS. 2013; 110: 3351-3356.

Di Agostino S., et al. Gain of function of mutant p53: the mutant p53/NF-Y protein complex reveals an aberrant transcriptional mechanism of cell cycle regulation. Cancer Cell. 2006; 10:191-202

D'Ambrogio A., et al. Specific miRNA stabilization by Gld2-catalyzed monoadenylation. Cell Rep. 2012; 27: 1537-45.

Doench JG., \& Sharp, P. A. Specificity of microRNA target selection in translational repression. Genes Dev. 2004; 18: 504-511. 
Doench JG., Petersen CP., \& Sharp PA. siRNAs can function as miRNAs. Genes Dev. 2003; 17: 438-442.

Duriez C., et al. The human BTG2/TIS21/PC3 gene: genomic structure, transcriptional regulation and evaluation as a candidate tumor suppressor gene. Gene. 2002; 282: $207-$ 214.

Elkon R., et al. E2F mediates enhanced alternative polyadenylation in proliferation. Genome Biol. 2012; 13:R59.

Feng Z., et al. Tumor suppressor p53 meets microRNAs. J Mol Cell Biol. 2011; 3: 44-50.

Fesler A., et al. The expanding regulatory universe of p53 in gastrointestinal cancer. F1000 Res. 2016; 5: 756-769.

Fields S., \& Jang SK. Presence of a potent transcription activating sequence in the p53 protein. Science 1990; 249: 1046-1049.

Fischer M. Census and evaluation of p53 target genes. Oncogene. 2017; 36: 3943-3956.

Fischer M., et al. The p53-p21-DREAM-CDE/CHR pathway regulates G2/M cell cycle genes. Nucleic Acids Res. 2016; 44: 164-174.

Fischer N., \& Weis K. The DEAD box protein Dhh1 stimulates the decapping enzyme Dcp1. EMBO J. 2002; 21: 2788-2797.

Fogal V., et al. Cell cycle-dependent nuclear retention of p53 by E2F1 requires phosphorylation of p53 at Ser315. EMBO J. 2005; 24: 2768-2782

Friedler A, et al. Modulation of binding of DNA to the C-terminal domain of $\mathrm{p} 53$ by acetylation. Structure. 2005; 13: 629-636.

Gatz SA., \& Wiesmuller L. p53 in recombination and repair. Cell Death Differ 2006; 13: $1003-1016$.

Garibaldi F., et al. Mutant p53 inhibits miRNA biogenesis by interfering with the microprocessor complex. Oncogene. 2016; 35: 3760-3770.

Ghildiyal M., \& Zamore PD. Small silencing RNAs: an expanding universe. Nat. Rev. Genet. 2009; 10: 94-108.

Giaccia AJ., \& Kastan MB. The complexity of p53 modulation: emerging patterns from divergent signals. Genes Dev. 1998; 12: 2973-2983. 
Giebler HA., Lemasson I., \& Nyborg JK. p53 recruitment of CREB binding protein mediated through phosphorylated CREB: a novel pathway of tumor suppressor regulation. Mol Cell Biol. 2000; 20: 4849-4858.

Gohler T., et al. Mutant p53 proteins bind DNA in a DNA structure-selective mode. Nucleic Acids Res. 2005; 33:1087-1100.

Gottlieb TM., et al. Cross-talk between Akt, p53 and Mdm2: possible implications for the regulation of apoptosis. Oncogene. 2002; 21: 1299-1303.

Gruber AR., et al. Cleavage factor Im is a key regulator of 30 UTR length. RNA Biol. 2012; 9: 1405-12.

Guardavaccaro D., et al. Arrest of G(1)-S progression by the p53-inducible gene PC3 is $\mathrm{Rb}$ dependent and relies on the inhibition of cyclin D1 transcription. Mol Cell Biol. 2000; 20:1797-1815.

Gudkov AV., \& Komarova EA. The role of p53 in determining sensitivity to radiotherapy. Nat. Rev. Cancer. 2003; 3: 117-129.

Guil S., \& Cáceres JF. The multifunctional RNA-binding protein hnRNP A1 is required for processing of miR-18a. Nat. Struct. Mol. Biol. 2007; 14: 591-596

Gurtner A., et al. Dysregulation of microRNA biogenesis in cancer: The impact of mutant p53 on Drosha complex activity. J Exp Clin Cancer Res. 20016; 35: 45-60.

Haase AD., et al. TRBP, a regulator of cellular PKR and HIV-1 virus expression, interacts with Dicer and functions in RNA silencing. EMBO Rep. 2005; 6: 961-967.

Hake LE., \& Richter JD. CPEB is a specificity factor that mediates cytoplasmic polyadenylation during Xenopus oocyte maturation. Cell. 1994; 79: 617-627.

Halees AS., et al. Global assessment of GU-rich regulatory content and function in the human transcriptome. RNA Biol. 2011; 8: 681-691.

Hamard P.J., Lukin D.J. \& Manfredi J.J. p53 basic C terminus regulates p53 functions through DNA binding modulation of subset of target genes. J. Biol. Chem. 2012; 287: 22397-22407.

Han J., et al. Molecular basis for the recognition of primary microRNAs by the DroshaDGCR8 complex. Cell. 2006; 125: 887-901.

Harrington EA., et al. pRB plays an essential role in cell cycle arrest induced by DNA damage. Proc Natl Acad Sci USA 1998; 95:11945-11950. 
Haupt Y., et al. Mdm2 promotes the rapid degradation of p53. Nature. 1997; 6630:296299.

He L., et al. A microRNA component of the p53 tumour suppressor network. Nature. 2007; 447:1130-1134.

Heintz K., et al. The role of p53 in cancer drug resistance and targeted chemotherapy. Oncotarget. 2017; 8: 8921-8949.

Helwak A., \& Tollervey D. Mapping the miRNA interactome by cross-linking ligation and sequencing of hybrids (CLASH). Nat Protoc. 2014; 9: 711-728.

Hermeking H. MicroRNAs in the p53 network: Micromanagement of tumour suppression. Nat Rev Cancer. 2012; 12: 613-626.

Hock AK., \& Vousden KH. The role of ubiquitin modification in the regulation of p53. Biochem Biophys. Acta. 2014; 1:137-149

Hoffman Y., et al. 3'UTR shortening potentiates microRNA-based repression of prodifferentiation genes in proliferating human cells. PLos Genet. 2016; 6: 10.1371/journal.pgen.1005879.

Hoffman Y., Pilpel Y., \& Oren M. microRNAs and Alu elements in the p53-Mdm2Mdm4 regulatory network. J Mol Cell Biol. 2014; 6: 192-197.

$\mathrm{Hu} \mathrm{W}$., et al. Negative regulation of tumor suppressor p53 by microRNA miR-504. Mol Cell. 2010; 38: 689-699.

Huarte J., et al. Transient translational silencing by reversible mRNA deadenylation. Cell. 1992; 69: 1021-1030.

Hudson CD., Morris PJ., \& Latchman DS. Brn-3a transcription factor blocks p53 mediated activation of pro-apoptotic target genes, Noxa and Bax, in vitro and in vivo to determine cell fate. J Biol Chem. 2004; 280: 11851-11858.

Jakymiw A., et al. Autoimmune targeting of key components of RNA interference. Arthritis Res. Ther. 2006; 8: R87.

Ji Z., et al. Progressive lengthening of 30 untranslated regions of mRNAs by alternative polyadenylation during mouse embryonic development. Proc Natl Acad Sci USA. 2009; 106: 7028-33.

Kalantari R., et al. Stable association of RNAi machinery is conserved between the cytoplasm and nucleus of human cells. RNA. 2016; 22: 1085-1098. 
Kastan MB., et al. A mammalian cell cycle checkpoint pathway utilizing p53 and GADD45 is defective in ataxia-telangiectasia. Cell. 1992; 71: 587-597.

Katoh T., et al. Selective stabilization of mammalian microRNAs by 3-adenylation mediated by the cytoplasmic poly(A) polymerase GLD-2. Genes Dev. 2009; 23:4 33-38.

Kearns S., et al. Two p53 tetramers bind one consensus DNA response element. Nucleic Acid Res. 2016; 44: 6185-6199.

Kim H., et al. p53 requires an intact C-terminal domain for DNA binding and transactivation. J. Mol. Biol. 2012; 415: 843-854.

Kim YK., Kim B., \& Kim VN. Re-evaluation of the roles of DROSHA, exportin-5, and DICER in microRNA biogenesis. PNAS. 2016; 113: 1881-1889.

Kleppe L., et al. Maternal 30UTRs: from egg to onset of zygotic transcription in Atlantic cod. BMC Genomics. 2012; 13: 443.

Krek A., et al. Combinatorial microRNA target predictions. Nat. Genet. 2005; 37: 495500 .

Krell J., et al. The role of TP53 in miRNA loading onto AGO2 and in remodeling the miRNA-mRNA interaction network. Lancet. 2015; 385: 15-20.

Kubbutat M.H., et al.Regulation of p53 stability by Mdm2. Nature. 1997; 387:299-303

Kuhn RM., et al. The UCSC Genome Browser Database. Nucleic Acids Res. 2009; 37:D755-61.

Kussie PH., et al. Structure of the MDM2 oncoprotein bound to the p53 tumor suppressor transactivation domain. Science. 1996; 274:948-953.

Kwak JE., et al. Mammalian GLD-2 homologs are poly(A) polymerases. Proc Natl Acad Sci USA. 2004, 101: 4407-4412.

Laptenko O., et al. The p53 C terminus controls site-specific DNA binding and promotes structural changes within the central DNA binding domain. Mol. Cell. 2015; 57: 10341046.

Lee C.-H., et al. Crystal structure of the conserved core of HIV-1 Nef complexed with Src family SH3 domain. Cell. 1996; 85: 931-942.

Lee CW, et al. Graded enhancement of p53 binding to CREB-binding protein (CBP) by multisite phosphorylation. Proc Natl Acad Sci USA. 2010; 107: 19290-19295. 
Lee D., \& C. Shin. Emerging roles of Drosha beyond primary microRNA processing. RNA Biology. 2017; 15:186-193.

Lee RC., \& Ambros V. The C. elegans heterochronic gene lin-4 encodes small RNAs with antisense complementarity to lin-14. Cell. 1993; 75: 843-854.

Lee Y., et al. The role of PACT in the RNA silencing pathway. EMBO J. 2006; 25: 522532.

Lerner LK., et al. Predominant role of DNA polymerase eta and p53-dependent translation synthesis in the survival of ultraviolet-irradiated human cells. Nucleic Acids Res. 2016; 45: 1270-1280.

Leveille N., et al. Selective inhibition of microRNA accessibility by RBM38 is required for p53 activity. Nat Commun. 2011; 2: 513.

Levine AJ., et al. The p53 pathway: what questions remain to be explored? Cell Death and Diff. 2006; 13: 1027-1036.

Lewis BP., et al. Prediction of mammalian microRNA targets. Cell. 2003; 115: 787-798.

Li XL., et al. Mutant p53 exerts oncogenic effects through microRNAs and their target gene networks. FEBS Letter. 2014; 588: 2610-2615.

Liao JY., et al. Deep sequencing of human nuclear and cytoplasmic small RNAs reveals an unexpectedly complex subcellular distribution of miRNAs and tRNA 3 ' trailers. PLoS One. 2010; 5: e10563.

Lill NL., et al. Binding and modulation of p53 by p300/CBP coactivators. Nature. 1997; 387: $823-827$

Liu G., \& Chen X. DNA polymerase eta, the product of the xeroderma pigmentosum variant gene and a target of p53, modulates the DNA damage checkpoint and p53 activation. Mol Cell Biol 2006; 26: 1398-1413.

Liu J., et al. Tumor suppressor p53 and its mutants in cancer metabolism. Cancer Letter. 2015; 356:197-203.

Liu, J., Hu J., \& Corey DR. Expanding the action of duplex RNAs into the nucleus: Redirecting alternative splicing. Nucleic Acids Res. 2012; 40: 1240-1250.

Liu K., Ling S., \& Lin WC. TopBP1 mediates mutant p53 gain of function through NF-Y and p63/p73. Mol Cell Biol. 2011; 31: 4464-4481

Li ZF., et al. Dynamic localization of mature microRNAs in Human nucleoli is influenced by exogenous genetic materials. PLoS ONE. 2013; 8: e70869. 
Lund E., \& Dahlberg JE. Substrate Selectivity of Exportin 5 and Dicer in the Biogenesis of MicroRNAs. Cold Spring Harb Symp Quant. Biol. 2006; 71: 59-66.

Luo Y., Hurwitz J., \& Massagué J. Cell-cycle inhibition by independent CDK and PCNA binding domains in p21Cip1. Nature 1995; 375: 159-161.

MacFarlane LA., \& Murphy PR. microRNA: biogenesis, function and role in cancer. Current Genomics. 2011; 11: 537-561.

MacLachlan TK., \& El-Deiry WS. Apoptotic threshold is lowered by p53 transactivation of caspase-6. Proc. Natl. Acad. Sci. USA . 2002; 99: 9492-9497.

Maier T, et al. Correlation of mRNA and protein in complex biological samples. FEBS Letters. 2009; 583: 3966-3973.

Marcon E., et al. miRNA and piRNA localization in the male mammalian meiotic nucleus. Chromosome Res. 2008; 16: 243-260.

Marine JC., \& Lozano G. Mdm2-mediated ubiquitylation: p53 and beyond. Cell Death Differ. 2010; 17:93-102.

Martin G., et al. Genome-wide analysis of pre-mRNA 30 end processing reveals a decisive role of human cleavage factor I in the regulation of 30 UTR length. Cell Rep. 2012; 1: 753-63.

Masamha CP., et al. CFIm25 links alternative polyadenylation to glioblastoma tumour suppression. Nature. 2014; 510: 412-6.

Matoulkova E., et al. The role of the 3 'untranslated region post-transcriptional regulation of protein expression in mammalian cells. RNA Biol. 2012; 95: 563-576.

Mayo LD., \& Donner DB. The PTEN, Mdm2, p53 tumor suppressor-oncoprotein network. Trends Biochem. Sci. 2002; 27: 462-467.

McGrew LL., \& Richter JD. Translational control by cytoplasmic polyadenylation during Xenopus oocyte maturation: Characterization of cis and trans elements and regulation by cyclin/MPF. EMBO J. 1990; 9: 3743-3751.

McKinney K., et al. p53 linear diffusion along DNA requires its C terminus. Mol. Cell. 2004; 16: 413-424.

McKinney K., \& Prives C. Efficient specific DNA binding by p53 requires both its central and C-terminal domains as revealed by studies with high-mobility group 1 protein. Mol. Cell. Biol. 2002; 22: 6797-6808. 
Melanson BD., et al. The role of mRNA decay in p53-induced gene expression. RNA. 2011; 12: 2222-2234.

Mignon F., et al. Untranslated regions of UTRs. Genome Biol. 2002; 3: 11897027.

Millevoi S., \& Vagner S. Molecular mechanisms of eukaryotic pre-mRNA 30 end processing regulation. Nucleic Acids Res. 2010; 38:2 757-7274.

Muller PA, \& Vousden KH. p53 mutations in cancer. Nat Cell Biol. 2013; 15:2-8.

Muller PA, et al. Mutant p53 regulates Dicer through p63-dependent and -independent mechanisms to promote an invasive phenotype. J Biol Chem. 2014; 289:122-132.

Nagata S., \& Golstein P. The Fas death factor. Science 1995; 267: 1449-1456.

Nam JW., et al. Global analyses of the effect of different cellular contexts on microRNA targeting. Mol Cell. 2014; 53: 1031-1043.

Nazeer FI., et al. p53 inhibits mRNA 3' processing through its interaction with the CstF/BARD1 complex. Oncogene. 2011; 30: 3073-3083.

Nishi K., et al. Human TNRC6A is an Argonaute-navigator protein for microRNAmediated gene silencing in the nucleus. RNA. 2013; 19: 17-35.

Okada C., et al. A high-resolution structure of the pre-microRNA nuclear export machinery. Science. 2009; 326: 1275-1279.

Okamura K., et al. The mirtron pathway generates microRNA-class regulatory RNAs in Drosophila. Cell. 2007; 130: 89-100.

Olivier M., et al. TP53 mutations in human cancers: origins, consequences, and clinical use. Cold Spring Harb. Perspec Biol. 2010. doi: 10.1101/cshperspect.a001008

Oren M. Decision making by p53: life, death and cancer. Cell Death Differ. 2003; 10 : 431-442.

Oren M., et al. Regulation of p53: intricate loops and delicate balances. Biochem. Pharmacol. 2002; 64: 865-871.

Parker R., \& Song H. The enzymes and control of eukaryotic mRNA turnover. Nat. Struct. Mol. Biol. 2004; 11: 121-127.

Pavletich NP., et al. The DNA-binding domain of p53 contains the four regions and the major mutation hot spots. Genes and development. 1993; 7: 2556-2564. 
Perron MP., \& Provost P. Protein interactions and complexes in human microRNA biogenesis and function. Front Biosci., 2008; 13: 2537-2547.

Pique M, et al. A combinatorial code for CPE-mediated translational control. Cell. 2008; 132: 434-448.

Piriyapongsa $\mathrm{J}$, et al. Origin and evolution of human microRNAs from transposable elements. Genetics. 2007; 176: 1323-1337.

Politz JC., Zhang F., \& Pederson T. MicroRNA-206 colocalizes with ribosome-rich regions in both the nucleolus and cytoplasm of rat myogenic cells. Proc. Natl. Acad. Sci. USA. 2006; 103: 18957-18962.

Porter JR., et al. p53 pulses diversify target gene expression dynamics in an mRNA half-lifedependent manner and delineate co-regulated target gene subnetworks. Cell Systems. 2016; 2: 272-282.

Proudfoot N. Poly(A) signals. Cell. 1991; 64:6 71-674.

Qian Y., \& Chen X. Tumor suppression by p53: making cells senescent. Histol. Histopathol. 2010; 25: 515-526.

Raver-Shapira N., et al. Transcriptional activation of miR-34a contributes to $\mathrm{p} 53$ mediated apoptosis. Mol Cell, 2007; 26:731-743.

Reyes-Gutierrez P., Ritland Politz JC., \& Pederson T. A mRNA and cognate microRNAs localize in the nucleolus. Nucleus .2014; 5: 636-642.

Robb GB., et al. Specific and potent RNAi in the nucleus of human cells. Nat. Struct. Mol. Biol. 2005; 12: 133-137.

Rouault J-P., et al. Identification of BTG2, an antiproliferative p53-dependent component of the DNA damage cellular response pathway. Nat Genet. 1996; 14: 482-486.

Ruard EM., et al., A proline-rich motif in p53 is required for transactivation-independent growth arrest as induced by Gas1. Proc. Natl. Acad. Sci. USA. 1997; 94: 4675-4680.

Ruby JG., Jan CH., \& Bartel DP. Intronic microRNA precursors that bypass Drosha processing. Nature. 2007; 448: 83-86.

Sachdeva M, et al. p53 represses c-Myc through induction of the tumor suppressor miR145. Proc Natl Acad Sci USA. 2009; 106: 3207-3212.

Salzman DW., et al. miR-34 activity is modulated through 5'-end phosphorylation in response to DNA damage. Nature Comm. 2015; 7: 10954. 
Sampath J., et al. Mutant p53 cooperates with ETS and selectively up-regulates human MDR1 not MRP1. J Biol Chem. 2001; 276: 39359-39367.

Sandberg R., et al. Proliferating cells express mRNAs with shortened 30 untranslated regions and fewer micro- RNA target sites. Science. 2008; 320:1 643-7.

Sengupta S., \& Harris CC. p53: traffic cop at the crossroads of DNA repair and recombination. Nat Rev Mol Cell Biol. 2005; 6: 44-55.

Simon R., Tassan JP., \& Richter JD. Translational control by poly(A) elongation during Xenopus development: differential repression and enhancement by a novel cytoplasmic polyadenylation element. Genes Dev. 1992; 6: 2580-2591.

Singh P., et al. Global changes in processing of mRNA 3'untranslated regions characterize clinically distinct cancer subtypes. Cancer Res. 2009; 69: 9422-9430.

Sheets MD., et al. The 3-untranslated regions of cmos and cyclin mRNAs stimulate translation by regulating cytoplasmic polyadenylation. Genes Dev. 1994; 8: 926-938.

Sheets MD., Ogg SC., \& Wickens MP. Point mutations in AAUAAA and the poly (A) addition site: effects on the accuracy and efficiency of cleavage and polyadenylation in vitro. Nucleic Acids Res. 1990; 18:5799-5805.

Shi Y., \& Manley JL. The end of the message: multiple protein-RNA interactions define the mRNA polyadenylation site. Genes Dev. 2015; 29:889-897.

Smalheiser NR, \& Torvik VI. Alu elements within human mRNAs are probable microRNA targets. Trends Genet. 2006; 22:532-536.

Smith JN., et al., The contribution of transactivation subdomains 1 and 2 to p53-induced gene expression is heterogeneous but not subdomain-specific. Neoplasia. 2007. 9: 1057-1065.

Spengler RM., et al. Elucidation of transcriptome-wide microRNA binding sites in human cardiac tissue by Ago2 HITS-CLIP. Nucleic Acid Res. 2016; 44: 7120-7131.

Song H., \& Xu Y. Gain of function of p53 cancer mutants in disrupting critical DNA damage response pathways. Cell Cycle. 2007; 6: 1570-1573.

Stambolic V., et al. Regulation of PTEN transcription by p53. Molecular Cell. 2001; 8: 317-325.

Sullivan KD., et al. Mechanisms of transcriptional regulation by p53. Cell Death and Diff. 2018; 25: $133-143$.

Thivierge C., et al. Alternative polyadenylation confers Pten mRNAs stability and resistance to microRNAs. Nucleic Acids Res. 2018. doi.org/10.1093/nar/gky666. 
Tian B., et al. A large-scale analysis of mRNA polyadenylation of human and mouse genes. Nucleic Acids Res. 2005; 33: 201-212.

Tian B., \& Graber JH. Signals for pre-mRNA cleavage and polyadenylation. Wiley Interdiscip Rev RNA. 2012; 3: 385-396.

Valencia-Sanchez MA., et al. Control of translation and mRNA degradation by miRNAs and siRNAs. Genes Dev. 2006; 20: 515-524.

Velten L., et al. Single-cell polyadenylation site mapping reveals 30 isoform choice variability. Mol Syst Biol. 2015; 11: 812.

Vishnu MR, et al. The poly(rC)-binding protein $\alpha \mathrm{CP} 2$ is a noncanonical factor in $\mathrm{X}$. laevis cytoplasmic polyadenylation. RNA. 2011; 17: 944-956.

Vousden KH., \& Prives C. Blinded by the light: The growing complexity of p53. Cell. 2009; 137:413-431.

Walter K., et al. Tumor suppressor p53 binds with high affinity to CTG.CAG trinucleotide repeats and induces topological alterations in mismatched duplexes. $\mathrm{J}$ Biol Chem. 2005; 280: 42497-42507.

Wang ET., et al. Alternative isoform regulation in human tissue transcriptomes. Nature. 2008; 456: 470-476.

Wang YY., et al. A novel mRNA 3'untranslated region translational control sequence regulates Xenopus Wee1 mRNA translation. Dev Biol. 2008; 317: 454-466.

Wang L., et al. A regulatory cytoplasmic poly(A) polymerase in Caenorhabditis elegans. Nature. 2002; 419: 312-316.

Wang XW., et al. GADD45 induction of a G2/M cell cycle checkpoint. Proc Natl Acad Sci USA. 1999; 96:3706-3711.

Weinmann L., et al. Importin 8 is a gene silencing factor that targets argonaute proteins to distinct mRNAs. Cell. 2009; 136: 496-507.

Wei Y., et al. Importin 8 regulates the transport of mature microRNAs into the cell nucleus. J. Biol. Chem. 2014; 289: 10270-10275.

Wightman, BHI., \& Ruvkun G. Posttranscriptional regulation of the heterochronic gene lin-14 by lin-4 mediated temporal pattern formation in C. elegans. Cell. 1993; 75: 855-862.

Winter J., \& Diederichs S. Argonaute proteins regulate microRNA stability: increased microRNA abundance by Argonaute proteins is due to microRNA stabilization. RNA Biol. 2011; 8:1149-1157. 
Wu GS., et al. KILLER/DR5 is a DNA damage-inducible p53-regulated death receptor gene. Nat. Genet. 1997; 17: 141-143.

$\mathrm{Wu} \mathrm{H}$., et al. A splicing-independent function of SF2/ASF in microRNA processing. Mol. Cell. 2010; 38: 67-77.

Yekta S., Shih IH., \& Bartel, DP. MicroRNA-directed cleavage of HOXB8 mRNA. Science. 2004; 304: 594-596.

Yi R., et al. Exportin-5 mediates the nuclear export of pre-microRNAs and short hairpin RNAs. Genes Dev. 2003; 17: 3011-3016.

Yin H., et al. Progress on the relationship between miR-125 family and tumorigenesis. Exp Cell Res. 2015; 339: 252-260.

Yuan Z, et al. Origin and evolution of a placental specific microRNA family in the human genome. BMC Evol. Biol. 2010; 10:346.

Xiang Y., et al. Comprehensive characterization of alternative polyadenylation in human cancer. JNCI J Natl Cancer Inst. 2018; 110: 1-11.

Zeng Y., \& Cullen BR. Structural requirements for pre-microRNA binding and nuclear export by exportin-5. Nucleic Acids Res. 2004; 32: 4776-4785.

Zhang C., et al. MicroRNA-339-5p inhibits colorectal tumorigenesis through regulation of the MDM2/p53 signaling. Oncotarget. 2014; 5: 9106-9117. 